\title{
Flatten the Curve! Modeling SARS-CoV-2/COVID-19 Growth in Germany at the County Level
}

\author{
Thomas Wieland ${ }^{1}$ \\ ${ }^{1}$ Karlsruhe Institute of Technology, Karlsruhe, Germany
}

Received: 14 May 2020/Accepted: 2 November 2020

\begin{abstract}
Since the emerging of the "novel coronavirus" SARS-CoV-2 and the corresponding respiratory disease COVID-19, the virus has spread all over the world. Being one of the most affected countries in Europe, in March 2020, Germany established several nonpharmaceutical interventions to contain the virus spread, including the closure of schools and child day care facilities (March 16-18, 2020) as well as a full "lockdown" with forced social distancing and closures of "nonessential" services (March 23, 2020). The present study attempts to analyze whether these governmental interventions had an impact on the declared aim of "flattening the curve", referring to the epidemic curve of new infections. This analysis is conducted from a regional perspective. On the level of the 412 German counties, logistic growth models were estimated based on daily infections (estimated from reported cases), aiming at determining the regional growth rate of infections and the point of inflection where infection rates begin to decrease and the curve flattens. All German counties exceeded the peak of new infections between the beginning of March and the middle of April. In a large majority of German counties, the epidemic curve has flattened before the "lockdown" was established. In a minority of counties, the peak was already exceeded before school closures. The growth rates of infections vary spatially depending on the time the virus emerged. Counties belonging to states which established an additional curfew show no significant improvement with respect to growth rates and mortality. Furthermore, mortality varies strongly across German counties, which can be attributed to infections of people belonging to the "risk group", especially residents of retirement homes. The decline of infections in absence of the "lockdown" measures could be explained by 1) earlier governmental interventions (e.g., cancellation of mass events, domestic quarantine), 2) voluntary behavior changes (e.g., physical distancing and hygiene), 3) seasonality of the virus, and 4) a rising but undiscovered level of immunity within the population. The results raise the question whether formal contact bans and curfews really contribute to curve flattening within a pandemic.
\end{abstract}

\section{Background}

The "novel coronavirus" SARS-CoV-2 ("Severe Acute Respiratory Syndrome Coronavirus 2 ") and the corresponding respiratory disease COVID-19 ("Coronavirus Disease 2019") caused by the virus initially appeared in December 2019 in Wuhan, Province Hubei, China. Since its emergence, the virus has spread over nearly all countries across the world. On March 12, 2020, the World Health Organization (WHO) declared the SARS-CoV2/COVID-19 outbreak a global pandemic (Lai et al. 2020, World Health Organization 2020b). As of May 10, 2020, 3,986,119 cases and 278,814 deaths had been reported 
worldwide. In Europe, the most affected countries are Spain, Italy, United Kingdom and Germany (European Centre for Disease Prevention and Control 2020).

The virus is transmitted between humans via droplets or through direct contact (Lai et al. 2020). In a very influential simulation study from March 2020, the Imperial College COVID-19 Response Team (Ferguson et al. 2020) suggested a series of public health measures aimed at slowing or stopping the transmission of the virus in absence of a vaccine or a successful therapy. These so-called nonpharmaceutical interventions (NPI) aim at reducing contact rates in the population, including social distancing and closures of schools and universities as well as the quarantine of infected persons. The Chinese government had imposed containment measures in the Provice Hubei already at the end of January 2020. This "lockdown" included a quarantine of the most affected city Wuhan and movement restrictions for the population as well as school closures (CNN 2020). In March 2020, nearly all European countries have introduced measures against the spread of Coronavirus. These measures range from appeals to voluntary behaviour changes in Sweden to strict curfews, e.g. in France and Spain (Deutsche Welle 2020a). The public health strategy to contain the virus spread is commonly known as "flatten the curve", which refers to the epidemic curve of the number of infections: "Flattening the curve involves reducing the number of new COVID-19 cases from one day to the next. This helps prevent healthcare systems from becoming overwhelmed. When a country has fewer new COVID-19 cases emerging today than it did on a previous day, that's a sign that the country is flattening the curve" (Johns Hopkins University 2020).

In Germany, due to the federal political system, measures to "flatten the curve" were introduced on the national as well as the state level. As the German "lockdown" has no single date, we distinguish here between four phases of NPIs, of which the main interventions were the closures of schools, child day care centers and most retail shops etc. in calendar week 12 (phase 2), and the nationwide establishment of a contact ban (attributed to phase 3), including forced social distancing and a ban of gatherings of all types, on March 23, 2020. The German states Bavaria, Saarland, and Saxony established additional curfews (see Table 1). Occasionally, these governmental interventions were criticized because of the social, psychological and economic impacts of a "lockdown" and/or the lack of its necessity (Capital 2020, Süddeutsche Zeitung 2020a, Tagesspiegel 2020a, Welt online 2020a). Apart from the economic impacts emerging from a worldwide recession (The Guardian 2020), the psychosocial consequences of movement restrictions and social isolation (resulting from NPIs) have also become apparent now in terms of an increase of several mental health illnesses (Carvalho Aguiar Melo, de Sousa Soares 2020, Mucci et al. 2020, Williams et al. 2020). The effects of (forced) isolation as well as school and child day care closures are also visible through a worldwide increase in domestic abuse (New York Times 2020), reported in Germany as well (Stuttgarter Zeitung 2020, Süddeutsche Zeitung 2020b).

It is therefore all the more important to know whether these restrictions really contributed to the flattening of the epidemic curve of Coronavirus in Germany (RKI 2020a). This question should be addressed from a regional perspective for two reasons.

1. In May 2020, the competences for the measures in Germany have shifted from the national to the state and regional (county) level. In the future, counties with more than 50 new infections per 100,000 in one week are expected to implement regional measures (see Table 1).

2. A spatial perspective allows the impact of the German measures of March 2020 to be identified.

In his statistical study, the mathematician Ben-Israel (2020) compares the epidemic curves of Israel, the USA and several European countries. These curves demonstrate a decline of new infections, regardless of the national measures to contain the virus spread. Furthermore, the study reveals the trend that the peak of infections is typically reached in the sixth week after the first reported case, while a decline of the curve starts in week eight. This occurs in all assessed countries on the national level, no matter whether a "lockdown" was established (e.g. Italy) or not (e.g. Sweden). 
Table 1: Main governmental nonpharmaceutical interventions with respect to COVID-19 pandemic in Germany

\begin{tabular}{|c|c|c|c|}
\hline Phase & Measure & Entry into force & $\begin{array}{l}\text { Competence } \\
\text { /level }\end{array}$ \\
\hline 1 & First quarantines of infected persons and suspected cases & February 2020 & nationwide \\
\hline $\begin{array}{l}\text { up to } \\
\text { CW }\end{array}$ & $\begin{array}{l}\text { Minister of health Spahn recommends cancellation } \\
\text { of large events ( } \geq 1,000 \text { participants) }\end{array}$ & $($ March 8, 2020) & \\
\hline \multirow[t]{2}{*}{$10 / 11$} & Bundesliga games behind closed doors ("ghost games") & March 11, 2020 & nationwide \\
\hline & $\begin{array}{l}\text { Speeches of chancellor Merkel and president Steinmeier, } \\
\text { recommondation to avoid social contacts and large events }\end{array}$ & (March 12, 2020) & \\
\hline 2 & Closure of schools, child day care centers and universities & March 16-18, 2020 & states \\
\hline \multirow[t]{2}{*}{$\begin{array}{l}\text { CW } \\
12\end{array}$} & $\begin{array}{l}\text { Closure of retail facilities (except for basic supply), } \\
\text { bars and leisure facilities }\end{array}$ & March $17-19,2020$ & states \\
\hline & Travel restrictions & March 17, 2020 & nationwide \\
\hline 3 & Curfew in Bavaria, Saarland and Saxony & March 21-23, 2020 & states \\
\hline $\begin{array}{l}\text { CW } \\
12 / 13 \\
\text { ("Lock- } \\
\text { down") }\end{array}$ & $\begin{array}{l}\text { Contact ban: ban of gatherings }>2 \text { people (including } \\
\text { political and religious gatherings), forced social } \\
\text { distancing (distance } \geq 1.5 \mathrm{~m} \text { ), closure of "nonessential" } \\
\text { services (e.g., gastronomy, hairdressers) }\end{array}$ & March 23, 2020 & nationwide \\
\hline 4 & Reopening of several retail facilities and services & April 20,2020 & states \\
\hline CW & Mandatory face masks in public transport and shops & April $22-29,2020$ & states \\
\hline 17 & $\begin{array}{l}\text { Further liberalizations; implementation of an "emergency } \\
\text { brake": lockdowns on the county level on condition of } \\
50 \text { new infections per } 100,000 \text { in one week }\end{array}$ & May 6, 2020 & nationwide \\
\hline
\end{tabular}

Source: own compilation based on an der Heiden, Hamouda (2020), Deutsche Welle (2020a,b), Tagesschau.de (2020a,b).

The focus of the present study is on the main nonpharmaceutical interventions with respect to the SARS-CoV-2/COVID-19 pandemic in Germany. This means the concrete "lockdown" measures affecting the social and economic life of the whole society (distinguishing from measures taken in most cases of infectious dieseases, such as quarantine of affected persons). In the terminology of the present study, these are the phase 2 and 3 measures, denoted in Table 1. Building upon the discrepancy outlined by Ben-Israel (2020), the present study addresses the following research questions:

- Pandemic or epidemic growth has a regional component due to regional infection hotspots or other behavorial or spatial factors. Thus, growth rates of infections may differ between regions in the same country (Chowell et al. 2014). In Germany, the prevalence of SARS-CoV-2/COVID-19 differs among the 16 German states and 412 counties, clearly showing "hotspots" in South German counties belonging to Baden-Wuerttemberg and Bavaria (RKI 2020a). Thus, the first question to be answered is: How does the growth rate of SARS-CoV-2/COVID-19 vary across the 412 German counties?

- The German measures to contain the pandemic entered into force nearly at the same time, especially in terms of closures of schools, childcare infrastructure and retailing (starting March 16/17, 2020) as well as the nationwide contact ban (starting March 23, 2020). Ben-Israel (2020) found a decline of new infection cases on the national level regardless of the Corona measures. To examine the effect of the German measures, we need to estimate the time of the peak and the declining of the curves of infection cases, respectively: At which date(s) did the epidemic curves of SARS-CoV-2/COVID-19 flatten in the 412 German counties?

- Regional prevalence and growth, as well as the mortality of SARS-CoV-2/COVID19 , are attributed within media discussions to several spatial factors, including population density or demographic structure of the regions (Welt online 2020b). Furthermore, the German measures differ on the state level, as three states - Bavaria, 
Saarland and Saxony - established additional curfews supplementing the other interventions (see Table 1). Focusing on growth rate and mortality, and addressing these regional differences, the third research question is: Which indicators explain the regional differences of SARS-CoV-2/COVID-19 growth rate and mortality on the level of the 412 German counties?

\section{Methodology}

\subsection{Logistic growth model}

According to Li (2018), in simple terms, an infectious disease spread (pandemic or epidemic) can be summarized as follows: At the beginning, one or more infectious individuals are introduced into a population of susceptibles (non-infected/healthy individuals). As the pathogen (e.g., virus) is transmitted from one individual to another, the number of infected individuals increases over time. Depending on the regarded pathogen/disease, infected individuals recover due to medical interventions and/or reactions of the individuals' immune system and, in many cases, gain partial or full immunity against the pathogen (e.g., through the development of antibodies against a virus). In other cases, infected people may also die from the disease. In all aforementioned cases and on condition of a stationary population, the number of susceptibles decreases and, thus, the number of new infections decreases as well. As a consequence, the pandemic/epidemic slows down and ends. The disease spread may also be contained by vaccination and/or other control and preventive measures. Note that, technically, one must distinguish between an infection and the disease which is (or may be) caused by the pathogen: "Disease is not the same as infection. Infection is said to have occurred when an organism successfully avoids innate defense mechanisms and stably colonizes a niche in the body. To establish an infection, the invader must first penetrate the anatomic and physiological barriers that guard the skin and mucosal surfaces of the host. Secondly, the organism must be able to survive in the host cellular milieu long enough to reproduce. This replication may or may not cause visible, clinical damage to the host tissues, symptoms that we call 'disease"' (Mak, Saunders 2006).

Analyzing the transmission and spreading process of infectious diseases involves the utilization of mathematical models. Pandemic growth can be modeled by deterministic models such as the SIR (susceptible-infected-recovered) model and its extensions, or by stochastic, phenomenological models such as the exponential or the logistic growth model. The former type of model does not depend on large empirical data on disease cases but requires additional information about the disease and the transmission process. The latter type of model is based on linear or nonlinear regression. Only empirical data of infections and/or confirmed cases of disease (or death) is required to estimate such models (Batista 2020a,b, Chowell et al. 2014, 2015, Li 2018, Ma 2020, Pell et al. 2018). Recently, there have already been several attempts to model the SARS-CoV-2 pandemic on the country (or even world) level, by using either the original or extended SIR model (Batista 2020b), the logistic growth model (Batista 2020a, Vasconcelos et al. 2020, Wu et al. 2020), or both (Zhou et al. 2020).

In this paper, we regard the spread of the Coronavirus primarily as an empirical phenomenon over space and time and ignore its epidemiological characteristics. We focus on 1) the regional growth speed of the pandemic and 2) the time when exponential growth ends and the infection rate decreases again. Apart from that, only infection cases and some further information are available, but not additional epidemiological information. Thus, the method of choice is a phenomenological regression model. In an early phase of an epidemic, when the number of infected individuals growths exponentially, an exponential function could be utilized for the phenomenological analysis (Ma 2020). However, officially reported SARS-CoV-2 infections in Germany (measured by the time of onset of symptoms) declined from mid-March. The corresponding reproduction number was estimated at $R=0.71$ based on the case reports as of May 6, 2020 (RKI 2020a). This indicates that the phase of exponential growth was exceeded at this time. Thus, a logistic growth model is used for the analysis of SARS-CoV-2 growth in the German counties.

The following representations of the logistic growth model are adopted from Batista 


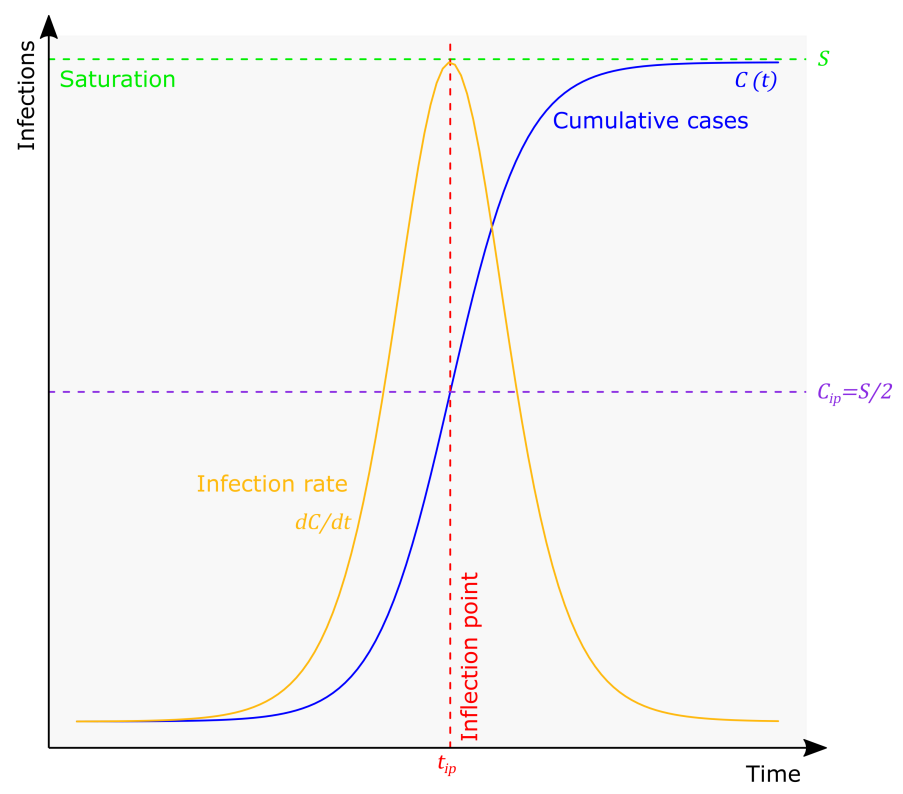

Figure 1: Logistic growth of an epidemic

(2020a), Chowell et al. (2014) and Tsoularis (2002). Unlike exponential growth, logistic growth includes two stages, allowing for a saturation effect. The first stage is characterized by an exponential growth of infections due to an unregulated spreading of the disease. As more infections accumulate, the number of at-risk susceptible persons decreases because of immunization, death, or behavioral changes as well as public health interventions. After the inflection point of the infection curve, when the infection rate is at its maximum, the growth decreases and the cumulative number of infections approximate its theoretical maximum, which is the saturation value (see Figure 1).

In the logistic growth model, the cumulative number of infected or diseased persons at time $t, C(t)$ is a function of time:

$$
C(t)=\frac{C_{0} S}{C_{0}+\left(S-C_{0}\right) \exp (-r S t)}
$$

where $C_{0}$ is the initial value of $C$ at time $0, r$ is the intrinsic growth rate, and $S$ is the saturation value.

The infection rate is the first derivative:

$$
\frac{d C}{d t}=r C\left(1-\frac{C}{S}\right)
$$

The inflection point of the logistic curve indicates the maximal infection rate before the growth declines, which means a flattening of the cumulative infection curve. The inflection point, $i p$, is equal to:

$$
i p=\frac{S}{2}
$$

at time

$$
t_{i p}=\frac{c}{r S}
$$

where:

$$
c=\ln \frac{C_{0}}{C-C_{0}}
$$

When empirical data (here: time series of cumulative infections) is available, the three model parameters $r, S$ and $C_{0}$ can be estimated empirically. 
We fit the models in a three-step estimation procedure including both OLS (Ordinary Least Squares) and NLS (Nonlinear Least Squares) estimation. The former is used for generating initial values for the iterative NLS estimation, making use of the linearization and stepwise parametrization of the logistic function. Following Engel (2010), the nonlinear logistic model (Equ. 1) can be transformed into a linear model (on condition that the saturation value is known) by taking the reciprocal on both sides, taking natural logarithms and rearranging the function:

$$
\ln \left(\frac{1}{C(t)}-\frac{1}{S}\right)=\ln \left(\frac{S-C_{0}}{S C_{0}}\right)-r S t
$$

The transformed dependent variable, $y_{i}^{*}$, can be expressed by a linear relationship with two parameters, the intercept $(\hat{b})$ and slope $(\hat{m})$ :

$$
\begin{gathered}
y_{i}^{*}=\ln \left(\frac{1}{C(t)}-\frac{1}{S}\right) \\
\hat{y}^{*}=\hat{b}+\hat{m} t
\end{gathered}
$$

In step 1, an approximation of the saturation value is estimated, which is necessary for the linear transformation of the model. Transforming the empirical values $C(t)$ according to Equ. (7), we have a linear regression model (Equ. 8). By utilizing bisection (Kaw et al. 2011), the best value for $S$ is searched minimizing the sum of squared residuals. The bisection procedure consists of 10 iterations, while the start values are set around the current maximal value of $C(t)$ (Interval: $[\max (C(t))+1 ; \max (C(t)) * 1.2]$ ).

The resulting preliminary start value for the saturation parameter, $\hat{S}_{\text {start }}$, is used in step 2. We transform the observed $C(t)$ using Equ. (7) with the preliminary value of $\hat{S}$ from step 1, $\hat{S}_{\text {start }}$. Another OLS model is estimated (Equ. 8). The estimated coefficients are used for calculating the start values of $\hat{r}$ and $\hat{C}_{0}$ for the nonlinear estimation (Engel 2010):

$$
\hat{r}_{\text {start }}=-\frac{\hat{m}}{\hat{S}_{\text {start }}}
$$

and

$$
\hat{C}_{0_{\text {start }}}=\frac{\hat{S}_{\text {start }}}{1+\hat{S}_{\text {start }} \exp (\hat{b})}
$$

In step 3, the final model fitting is done using Nonlinear Least Squares (NLS), while inserting the values from steps 1 and $2, \hat{S}_{\text {start }}, \hat{C}_{0_{\text {start }}}$ and $\hat{r}_{\text {start }}$, as start values for the iterative process. The NLS fitting uses the default Gauss-Newton algorithm (Ritz, Streibig 2008) with a maximum of 500 iterations.

Using the estimated parameters $\hat{r}, \hat{C}_{0}$ and $\hat{S}$, the inflection point of each curve is calculated via equations (3) to (5). The inflection point $t_{i p}$ is of unit time (here: days) and assigned to the respective date $t_{i p_{\text {date }}}$ (YYYY-MM-DD). Based on this date, the following day $t_{i p_{\text {date }+1}}$ is the first day after the inflection point at which time the infection rate has decreased again. For graphical visualization, the infection rate is also computed using Equ. (2).

\subsection{Estimating the dates of infection}

In the present study, we use the daily updated data on confirmed SARS-CoV-2/COVID-19 cases, provided by federal authorities, the German Robert Koch Institute (RKI) (RKI 2020b). This dataset includes all persons who have been tested positive on the SARSCoV-2 virus using a PCR (polymerase chain reaction) test and reported from local health authorities to the RKI. However, one must consider that neither the volume of tests nor the criteria for conducting a test are constant over time: Up to and including May 2020, almost exclusively people with acute respiratory symptoms were tested for SARS-CoV-2, as, with few exceptions, the presence of relevant symptoms is an exclusion criterion for testing in the RKI guidelines for medical doctors (IBBS 2020). In other words, this testing policy is targeted at the disease (COVID-19), not the virus (SARS-CoV-2). Thus, most of the cases in the present data are COVID-19 sufferers, whilst asymptomatic infected 
people and individuals with milder course are underrepresented. In the vast majority of cases, the date of onset of symptoms is reported in the dataset as well (an der Heiden, Hamouda 2020). The test volume was increased heavily from calendar week $11(127,457$ tests) to 12 (348,619 tests) but remains in the same order of magnitude until calendar week 18 (300,000-400,000 tests per week) (RKI 2020c).

The dataset used here is from May 5, 2020 and includes 163,798 cases. This data includes information about age group, sex, the related place of residence (county) and the date of report (Variable Meldedatum). The reference date in the dataset (Variable Refdatum) is either the day the disease started, which means the onset of symptoms, or the date of report (an der Heiden, Hamouda 2020). The date of onset of symptons is reported in the majority of cases (108,875 and $66.47 \%$, respectively).

The date of infection, which is of interest here, is either unknown or not included in the official dataset. Thus, it is necessary to estimate the approximate date of infection dependent on two time periods: the time between the infection and the onset of symptons (incubation period) and the delay between onset of symptoms and official report (reporting delay). From the 108,875 cases where the onset of the symptoms is known, we can calculate the mean reporting delay as 6.84 days. Additionally, we assume an incubation period of five days. This is a rather conservative assumption (which means a relatively short time period) referring to the current epidemiological estimates (see Table 2). In their model-based scenario analysis towards the total number of diseases and deaths, the RKI also assumes an average incubation period of five days (an der Heiden, Buchholz 2020). Taking into account incubation period and reporting delay, there is an average all-over delay between infection and reporting of about 12 days (see Figure 2).

But this is just one side of the coin. As an inspection of the case data reveals, the delay differs by case characteristics (age group, sex) and counties. In their current prognosis, the RKI estimates the dates of onset of symptoms by Bayesian nowcasting based on the reporting date, but not taking into account the incubation time. The RKI nowcasting model incorporates delays of reporting depending on age group and sex, but not including spatial (county-specific) effects (an der Heiden, Hamouda 2020). Exploring the dataset used here, we see obvious differences in the reporting delay with respect to age groups and sex. There seems to be a tendency of lower reporting delays for young children and older infected individuals (see Table 3). Taking a look at the delays between onset of symptoms and reporting date on the level of the 412 counties (not shown in table), the values range between 2.39 days (Würzburg city) and 17.0 days (Würzburg county).

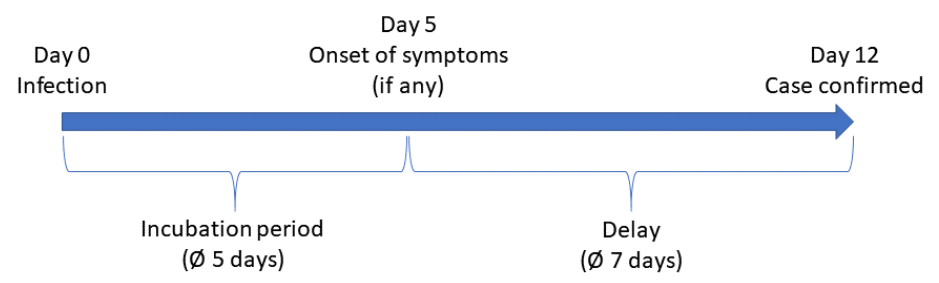

Figure 2: Time between infection and reporting of case

Table 2: Studys estimating the incubation period of SARS-CoV-2/COVID-19

\begin{tabular}{lccccccc}
\hline Study & $\mathrm{n}$ & Distribution & Mean (CI95) & SD (CI95) & Median (CI95) & Min. & Max. \\
\hline Backer et al. (2020) & 88 & Weibull & NA & $2.3(1.7,3.7)$ & $6.4(5.6,7.7)$ & NA & NA \\
Lauer et al. (2020) & 181 & Lognormal & 5.5 & $1.52(1.3,1.7)$ & $5.1(4.5,5.8)$ & NA & NA \\
Leung (2020) & $175(\mathrm{a})$ & Weibull & $1.8(1.0,2.7)$ & NA & NA & NA & NA \\
& $175(\mathrm{~b})$ & Weibull & $7.2(6.1,8.4)$ & NA & NA & NA & NA \\
Li et al. (2020) & 10 & Lognormal & $5.2(4.1,7.0)$ & NA & NA & NA & NA \\
Linton et al. (2020) & 158 & Lognormal & $5.6(5.0,6.3)$ & $2.8(2.2,3.6)$ & $5.0(4.4,5.6)$ & 2 & 14 \\
Sun et al. (2020) & 33 & NA & 4.5 & NA & NA & NA & NA \\
Xia et al. (2020) & 124 & Weibull & $4.9(4.4,5.4)$ & NA & NA & NA & NA \\
\hline
\end{tabular}

Notes: $(\mathrm{a})=$ Travelers to Hubei, $(\mathrm{b})=$ Non-Travelers. Source: own compilation. 
Table 3: Delay between onset of symptoms and official report by age group and sex

\begin{tabular}{llcc}
\hline Age group & Sex & \multicolumn{2}{c}{$\begin{array}{c}\text { Delay between onset of symptoms and } \\
\text { reporting date [days] }\end{array}$} \\
& & Mean & 5.68 \\
\hline A00-A04 & female & 5.82 & 5.34 \\
A05-A14 & female & 6.09 & 5.59 \\
A15-A34 & female & 6.82 & 5.98 \\
A35-A59 & female & 7.00 & 6.22 \\
A60-A79 & female & 7.08 & 5.83 \\
A80+ & female & 5.10 & 9.79 \\
unknown & female & 8.71 & 5.98 \\
A00-A04 & male & 5.93 & 5.12 \\
A05-A14 & male & 6.04 & 5.52 \\
A15-A34 & male & 6.78 & 5.90 \\
A35-A59 & male & 7.18 & 6.14 \\
A60-A79 & male & 7.20 & 5.84 \\
A80+ & male & 5.70 & 8.42 \\
unknown & male & 9.86 & 2.39 \\
A00-A04 & unknown/diverse & 3.50 & 5.20 \\
A05-A14 & unknown/diverse & 4.00 & 4.87 \\
A15-A34 & unknown/diverse & 6.44 & 5.51 \\
A35-A59 & unknown/diverse & 6.95 & 5.87 \\
A60-A79 & unknown/diverse & 7.36 & 11.40 \\
A80+ & unknown/diverse & 6.50 & 3.58 \\
unknown & unknown/diverse & 9.60 & 5.90 \\
\hline & all-over & 6.84 & \\
\hline
\end{tabular}

Source: own calculation based on data from RKI (2020b). Note: The date of onset of symptoms is known for $108,875(66.47 \%)$ of 163,798 cases in the dataset.

For the estimation of the dates of infection, it is necessary to distinguish between the cases where the date of symptom onset is known or not. In the former case, no assumption must be made towards the delay between onset of symptoms and date report. The calculation is simply:

$$
\hat{d} i_{i}=d o_{i}-i n c p
$$

where $\hat{d} i_{i}$ is the estimated date of infection of case $i, d o_{i}$ is the date of onset of symptoms reported in the RKI dataset and incp is the average incubation period equal to five (days).

For the 54,923 cases without information about onset of symptoms, we estimate this delay based on the 108,875 cases with known delays. As the reporting delay differs between age group, sex and county, the following dummy variable regression model is estimated (stochastic disturbance term is not shown):

$$
\hat{d}_{a s c}=\alpha+\sum_{a}^{A-1} \beta_{a} D_{\text {agegroup }_{a}}+\sum_{s}^{S-1} \gamma_{s} D_{\operatorname{sex}_{s}}+\sum_{c}^{C-1} \delta_{c} D_{\text {county }_{c}}
$$

where $\hat{d} s_{a s c}$ is the estimated delay between onset of symptoms and report depending on age group $a$, sex $s$ and county $c, D_{\text {agegroup }_{a}}$ is a dummy variable indicating age group $a, D_{\operatorname{sex}_{s}}$ is a dummy variable indicating sex $s, D_{\text {county }_{c}}$ is a dummy variable indicating county $c, A$ is the number of age groups, $S$ is the number of sex classifications, $C$ is the number of counties and $\alpha, \beta, \gamma$ and $\delta$ are the regression coefficients to be estimated.

Taking into account the delay estimation, if the onset of symptoms is unknown, the date of infection of case $i$ is estimated via:

$$
\hat{d} i_{i}=d r_{i}-\hat{d} s_{a s c}-i n c p
$$

where $d r_{i}$ is the date of report in the RKI dataset. 


\subsection{Models of regional growth rate and mortality}

To test which variables predict the intrinsic growth rate and the regional mortality of SARS-CoV-2/COVID-19, respectively, two regression models were estimated. In the first model with the intrinsic growth rate $r$ as dependent variable, we include the following predictors:

- In the media coverage about regional differences with respect to COVID-19 cases in Germany, several experts argue that a lower population density and a higher share of older population reduce the spread of the virus, with the latter effect being due to a lower average mobility (Welt online 2020b). It is well known that human mobility potentially increases the spread of an infectious disease. Also work-related commuting and tourism are considered as drivers of virus transmission (Charaudeau et al. 2014, Dalziel et al. 2014, Findlater, Bogoch 2018). To test these effects, four variables are included into the model: 1) The population density (POPDENS), 2) the share of population of at least 65 years $(P O P S 65), 3)$ an indicator for the intensity of commuting ( $C M I)$ formulated by Guth et al. (2010), and 4) the number of annual tourist arrivals per capita $(T O U R)$ for each county. All variables were calculated based on official statistics for the most recent year (2018/2019) (Destatis 2020a,b,c).

- In the media coverage, the lower prevalence in East Germany is also explained by 1) a different vaccination policy in the former German Democratic Republic and 2) a lower affinity towards carnival events as well as 3) less travelling to ski resorts due to lower incomes (Welt online 2020b). Thus, a dummy variable (1/0) for East Germany is included in the model $(E A S T)$.

- We test for the influence of different governmental interventions by including dummy variables for the states ("Länder") Bavaria $(B V)$, Saarland $(S L)$, Saxony $(S X)$ and North Rhine Westphalia $(N R W)$, as well as Baden-Wuerttemberg $(B W)$. Unlike the other 13 German states, the first three states established a curfew additional to the other measures at the time of phase 3 , as is identified in the present study. Like Bavaria, North Rhine Westphalia and Baden-Wuerttemberg belong to the "hotspots" in Germany, with the latter state having a prevalence similar to Bavaria. Saxony has a prevalence below the national average (RKI 2020a).

- Apart from any interventions, when a disease spreads over time, also the susceptible population must decrease over time. As more and more individuals get infected (maybe causing temporal or lifelong immunization or, in other cases, death), there are continually fewer healthy people to get infected ( $\mathrm{Li} 2018$ ) (see also Section 2.1). Consequently, regional growth must decrease with increasing regional prevalence and over time (and vice versa). In the specific case of SARSCoV-2/COVID-19, the outbreak differs between German counties (starting with "hotspots" like Heinsberg or Tirschenreuth county). Differences in growth may be due to different periods of time the virus is present and differences in the corresponding prevalence. Thus, two control variables are included in the model, the county-specific prevalence $(P R V)$ and the number of days since the first (estimated) infection $(D A Y S)$.

In the second model for the explanation of regional mortality $(M R T)$, five more independent variables have to be incorporated:

- From the epidemiological point of view, the "risk group" of COVID-19 for severe courses (and even deaths) is defined as people of 60 years and older. The arithmetic mean of deceased attributed to COVID-19 is equal to 81 years (median: 82 years). Out of 6,831 reported deaths on May $52020,6,524$ were of age 60 or older $(95.51 \%)$. This is, inter alia, because of outbreaks in residential homes for the elderly (RKI 2020a). Thus, the raw data from the RKI (RKI 2020b) was used to calculate the share of confirmed infected individuals of age 60 or older in all infected persons for each county (INFS60), which is included into the regression model for regional mortality. 
- Several health-specific variables are found to influence the mortality risk (as well as the risk of severe course) of COVID-19. These individual-specific risk factors include, inter alia, diabetes, obesity, other respiratory diseases, or smoking (Engina et al. 2020, Selvan 2020). There are several possible health indicators which are unfortunately not available for German counties. Thus, the average health situation is captured by incorporating the average regional life expectancy into the model $(L E X P)$, which is made available by the German Federal Institute for Research on Building, Urban Affairs and Spatial Development (BBSR 2020).

- On the regional level, air pollution was found to be a contributing factor to COVID19 fatality (Ogen 2020, Wu et al. 2020). According to Wu et al. (2020), the regional air pollution with respect to particulate matter (annual mean of daily $P M_{10}$ values, unit: $\mu \mathrm{g} / \mathrm{m}^{3}$ ) is included into the model (PM10). Since Ogen (2020) shows a correlation between nitrogen dioxide concentration and COVID-19 fatality, this type of air pollution (annual mean of daily $\mathrm{NO}_{2}$ values, unit: $\mu \mathrm{g} / \mathrm{m}^{3}$ ) is incorporated into the model as well (NO2). Both air quality indicators are made available by the German Environment Agency (UBA 2020a) on the level of single monitoring stations. These stations are available geocoded (UBA 2020b) and have been assigned to the German counties via a nearest neighbor join. Thus, the county-level values of both indicators equal the values of the nearest monitoring station.

- The intrinsic growth rate of each county is incorporated into the model as well. Considering the chronology of an infectious disease spread, there must be a reciprocal relationship between growth speed and mortality: The more individuals die in the context of the regarded disease, the fewer susceptibles are left to be infected, resulting in a deceleration of the pandemic spread (Li 2018) (see also Section 2.1). Thus, there must be a negative correlation between mortality and growth rate, all other things being equal. Consequently, the county-specific intrinsic growth rate $(r)$ is included as control variable.

See Table 4 for all variables included into the models. All continuous variables, including the dependent variables ( $r$ and $M R T$, respectively), were transformed via natural logarithm in the regression analysis. This leads to an interpretation of the regression coefficients in terms of elasticities and semi-elasticities (Greene 2012). Two variants were estimated for the growth rate model (with and without dummy variables) and three for the mortality model (with and without growth rate as well as a third model including both growth rate and dummy variables). The minimum significance level was set to $p \leq 0.1$. In the first step, the regression models were estimated using an Ordinary Least Squares (OLS) approach and tested with respect to multicollinearity using variance inflation factors (VIF) with a critical value equal to five (Greene 2012).

However, SARS-CoV-2/COVID-19 cases are obviously not evenly distributed across all German counties as the disease spread started in a few "hotspots" in Bavaria, BadenWuerttemberg and North Rhine Westphalia (RKI 2020a, Tagesspiegel 2020b). Of course, an infectious disease can be transmitted across county borders, in particular, by contact between residents of one region and a nearby region. As a consequence, it is to be expected that indicators of disease spread - such as the regarded variables growth rate and mortality - are similar between nearby regions. Thus, further model-based analyses require considering possible spatial autocorrelation in the dependent variables (Griffith 2009). Consequently, both dependent variables were tested for spatial autocorrelation using Moran's I-statistic and the model estimation was repeated using a spatial lag model. In this type of regression model, spatial autocorrelation is modeled by a linear relationship between the dependent variable and the associated spatially lagged variable, which is a spatially weighted average value of the nearby objects. The influence of spatial autocorrelation is captured by adding a further parameter, $\rho$, to the regression equation, which is also tested for significance. Spatial linear regression models are not fitted by OLS but by Maximum Likelihood (ML) estimation. Both Moran's I and the spatial lag model require a weighting matrix to define the proximity of the regarded spatial object to nearby objects (Chi, Zhu 2008, Rusche 2008). Here, the weighting matrix for the spatial object (county $i$ ) was defined as all adjacent counties. 
Table 4: Variables in the regression models for growth rate and mortality

\begin{tabular}{|c|c|c|c|}
\hline Variable & & Calculation/unit & Data source \\
\hline$r$ & Intrinsic growth rate & see Section 2.1 & $\begin{array}{l}\text { own calculation based on } \\
\text { RKI }(2020 \mathrm{~b})\end{array}$ \\
\hline$M R T$ & $\begin{array}{l}\text { Mortality cumulative } \\
\quad \text { (Porta 2008) }\end{array}$ & $\frac{D_{i}}{p o p_{i}} * 100000$ & $\begin{array}{l}\text { own calculation based on } \\
\text { RKI (2020b), Destatis }(2020 \mathrm{~b})\end{array}$ \\
\hline$P R V$ & $\begin{array}{l}\text { Prevalence cumulative } \\
\text { (Porta 2008) }\end{array}$ & $\frac{C_{i}}{\text { pop }_{i}} * 100000$ & $\begin{array}{l}\text { own calculation based on } \\
\text { RKI (2020b), Destatis (2020b) }\end{array}$ \\
\hline$D A Y S$ & $\begin{array}{l}\text { Time since first } \\
\text { infection }\end{array}$ & days (discrete) & $\begin{array}{c}\text { own calculation based on } \\
\text { RKI (2020b) }\end{array}$ \\
\hline POPDENS & Population density & $\frac{p o p_{i}}{A_{i}}$ & $\begin{array}{c}\text { own calculation based on } \\
\text { Destatis }(2020 \mathrm{~b})\end{array}$ \\
\hline POPS65 & $\begin{array}{l}\text { Share of population } \\
\text { age } 65 \text { or older }\end{array}$ & $\frac{p_{0 p} p_{65+i}}{p o p_{i}} * 100$ & $\begin{array}{l}\text { own calculation based on } \\
\text { Destatis }(2020 \mathrm{~b})\end{array}$ \\
\hline$C M I$ & $\begin{array}{l}\text { Intensity of commuting } \\
\text { (Guth et al. 2010) }\end{array}$ & $\frac{C M_{\text {out }_{i}}+C M_{\text {in }_{i}}}{L_{r e s_{i}}+L_{\text {work }}}$ & $\begin{array}{l}\text { own calculation based on } \\
\text { Destatis (2020c) }\end{array}$ \\
\hline TOUR & Tourist density & $\frac{T_{i}}{p o p_{i}} * 1000$ & $\begin{array}{l}\text { own calculation based on } \\
\text { Destatis }(2020 a, b)\end{array}$ \\
\hline INFS60 & $\begin{array}{l}\text { Share of infected age } \\
60 \text { or older in all } \\
\text { infected persons }\end{array}$ & $\frac{C_{60+i}}{C_{i}} * 100$ & $\begin{array}{l}\text { own calculation based on } \\
\text { RKI (2020b) }\end{array}$ \\
\hline$L E X P$ & Life expectancy & years $($ mean $)$ & BBSR (2020) \\
\hline PM10 & Air pollution $P M_{10}$ & $\mu g / m^{3}$ (annual mean) & UBA $(2020 a, b)$ \\
\hline NO2 & Air pollution $\mathrm{NO}_{2}$ & $\mu g / m^{3}$ (annual mean) & UBA $(2020 a, b)$ \\
\hline$E A S T$ & Dummy for East Germany & $1=$ East Germany, else 0 & \\
\hline$B V$ & Dummy for Bavaria & $1=$ Bavaria, else 0 & \\
\hline$S L$ & Dummy for Saarland & $1=$ Saarland, else 0 & \\
\hline$S X$ & Dummy for Saxony & $1=$ Saxony, else 0 & \\
\hline$N R W$ & $\begin{array}{l}\text { Dummy for North Rhine } \\
\text { Westphalia }\end{array}$ & $\begin{aligned} 1= & \text { North Rine West- } \\
& \text { phalia, else } 0\end{aligned}$ & \\
\hline$B W$ & $\begin{array}{l}\text { Dummy for Baden-Wuert- } \\
\text { temberg }\end{array}$ & $\begin{array}{c}1=\text { Baden-Wuerttem- } \\
\text { berg, else } 0\end{array}$ & \\
\hline
\end{tabular}

Note: $C_{i}$ is the cumulative number of reported SARS-CoV-2/COVID-19 cases in county $i, D_{i}$ is the cumulative number of reported deaths attributed to COVID-19 in county $i, C_{60+}{ }_{i}$ is the cumulative number of reported infected persons of age 60 or older in county $i, \operatorname{emphpop}_{i}$ is the population of county $i, A_{i}$ is the area of county $i$, emphpop $65+_{i}$ is the number of inhabitants of county $i$ of age 65 or older,

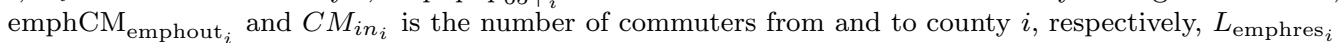
and $L_{\text {emphwork }_{i}}$ is the number of employees whose place of residence is county $i$ and whose place of work is county $i$, respectively.

\subsection{Software}

The analysis in this study was executed in $\mathrm{R}$ ( $\mathrm{R}$ Core Team 2019), version 3.6.2. The parametrization of logistic growth models was done using own functions for the OLS estimation based on the description in Engel (2010) and the nls () function for the final NLS estimation. For the steps of the regression analyses and presentation of results, the packages car (Fox, Weisberg 2019), REAT (Wieland 2019), spdep (Bivand et al. 2013), and stargazer (Hlavac 2018) were used. For creating maps, QGIS (QGIS Development Team 2019), version 3.8, was used, including the plugin NNJoin (Tveite 2019) for one further analysis.

\section{Results}

\subsection{Estimation of infection dates and national inflection point}

Figure 3 shows the estimated dates of infection and dates of report of confirmed cases and deaths for Germany. The curves are not shifted exactly by the average delay period 


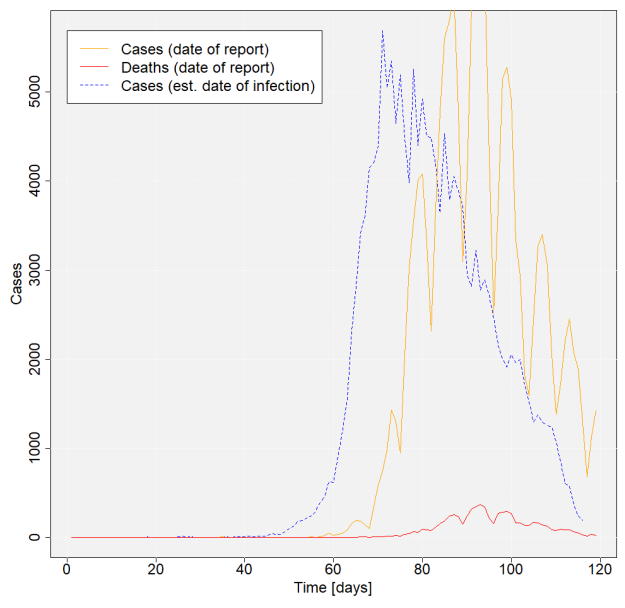

(a) Daily cases

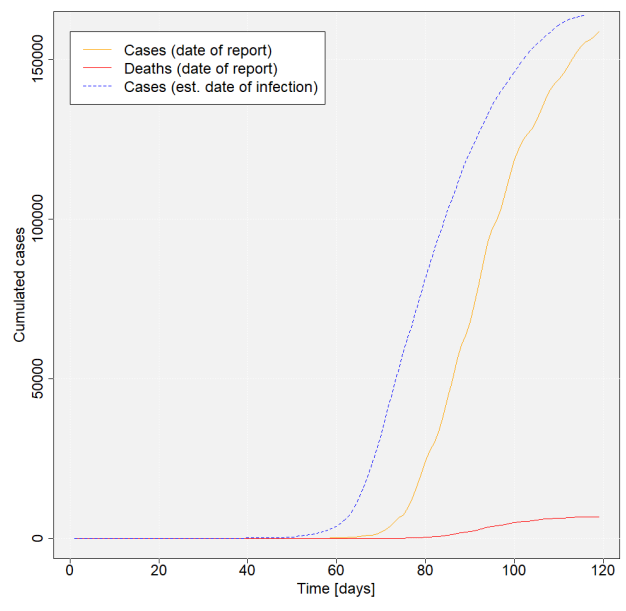

(b) Cumulative cases

Figure 3: Reported SARS-CoV-2 infections in Germany over time (dates of report vs. estimated dates of infection)

Source: own illustration.

Data source: own calculations based on RKI (2020b)

Table 5: Date of inflection point depending on assumed incubation period

\begin{tabular}{lcccc}
\hline Study & Median of incubation & \multicolumn{3}{c}{ Date of inflection point } \\
& time (CI-95) & Lower & Median & Upper \\
\hline Linton et al. (2020) & $5.0(4.4,5.6)$ & $2020-03-20$ & $2020-03-20$ & $2020-03-19$ \\
Backer et al. (2020) & $6.4(5.6,7.7)$ & $2020-03-20$ & $2020-03-19$ & $2020-03-17$ \\
\hline
\end{tabular}

Source: own calculation based on data from RKI (2020b).

because of the different delay times with respect to case characteristics and county. The average time interval between estimated infection and case reporting is $\bar{x}=11.92$ [days] $(S D=5.21)$. When applying the logistic growth model to the estimated dates of infection in Germany, the inflection point for Germany as a whole is on March 20, 2020.

Before switching to the regional level, we take into account the statistical uncertainty resulting from the estimation of the infection dates. About one third of the delay values for the time between onset of symptoms and case reporting was estimated by a stochastic model. Furthermore, the estimates of SARS-CoV-2/COVID-19 incubation period differ from study to study. This is why in the present case a conservative - which means a small - value of five days was assumed. Thus, we compare the results when including 1) the $95 \%$ confidence intervals of the response from the model in Equ. (12), and 2) the $95 \%$ confidence intervals of the incubation period as estimated by Linton et al. (2020). Figure 4 shows three different modeling scenarios, the mean estimation and the lower and upper bound of incubation period and delay time, respectively. The lower bound variant incorporates the lower bound of both incubation period and delay time, resulting in smaller delay between infection and case reporting and, thus, a later inflection point. The upper bound shows the counterpart. On the basis of the upper bound, the inflection point is already on March 19. Using the higher values of incubation period estimated by Backer et al. (2020), the upper bound results in an inflection point on March 17, while the lower bound variant leads to the turn on March 20. Considering confidence intervals of incubation period and delay time, the inflection point for the whole of Germany can be estimated between March 17 and March 20, 2020 (see Table 5). 


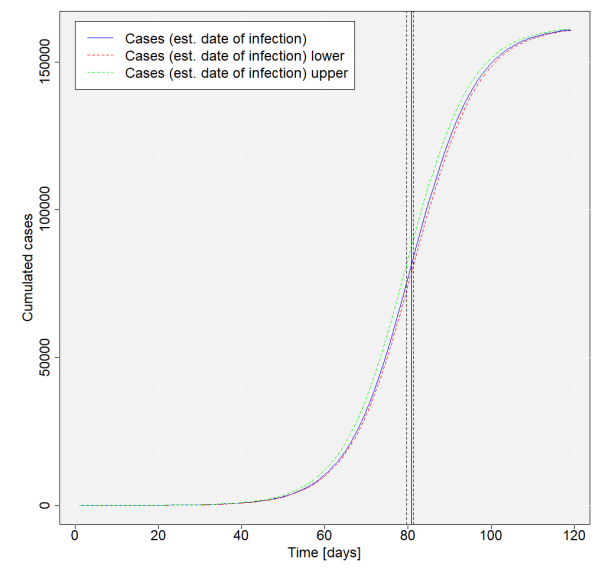

Figure 4: Estimated logistic growth model (including inflection point) for cumulative SARS-CoV-2 infections in Germany (based on estimated dates of infection) incorporating upper and lower bounds (95\%-CI)

Source: own illustration. Data source: own calculations based on RKI (2020b)

\subsection{Estimation of growth rates and inflection points on the county level}

Figure 5 shows the estimated intrinsic growth rates $(r)$ for the 412 counties. Figure 6 provides six examples of the logistic growth curves with respect to four counties identified as "hotspots" (Tirschenreuth, Heinsberg, Greiz and Rosenheim) and two counties with a low prevalence (Flensburg and Uckermark). There are obvious differences in the growth rates, following a spatial trend: The highest growth rates can be found in counties in North Germany (especially Lower Saxony and Schleswig-Holstein) and East Germany (especially Mecklenburg-Western Pomerania, Thuringia and Saxony). To the contrary, the growth rates in Baden-Wuerttemberg and North Rine Westphalia appear to be quite low. Taking a look at the time since the first estimated infection date in the German counties (see Figure 7a), the growth rates tend be much smaller the longer since the disease appeared in the county.

The regional inflection points indicate the day with the local maximum of infection rate. From this day forth, the exponential disease growth turns into degressive growth. In Figure $7 \mathrm{~b}$, the dates of the first day after the regional inflection point are displayed. The dates are categorized according to the coming into force of relevant nonpharmaceutical interventions (see Table 1). Table 6 summarizes the number of counties and the corresponding population shares by these categories. Figure 8 shows the intrinsic growth rate ( $y$ axis) and the day after the inflection point (colored points) against time ( $x$ axis). Figure 9 shows the same information against regional prevalence ( $x$ axis).

In 255 of 412 counties $(61.89 \%$ ) with 54.58 million inhabitants ( $65.66 \%$ of the national population), the SARS-CoV-2/COVID-19 infections had already decreased before phase 3 of measures came into force on March 23, 2020. In a minority of counties (51, 12.38\%),

Table 6: German counties by first day after inflection point

\begin{tabular}{lcccc}
\hline First day after inflection point & Counties [no.] & Counties [\%] & Population [Mill.] & Population [\%] \\
\hline Before March 13 & 6 & 1.46 & 0.98 & 1.17 \\
March 13 to March 16 & 45 & 10.92 & 8.27 & 9.95 \\
March 17 to March 20 & 138 & 33.50 & 31.03 & 37.33 \\
March 21 to March 22 & 66 & 16.02 & 14.30 & 17.20 \\
March 23 to April 19 & 157 & 38.11 & 28.54 & 34.34 \\
Sum & 412 & 100 & 83.13 & 100 \\
\hline
\end{tabular}

Source: own illustration. Data source: own calculations based on RKI (2020b) 


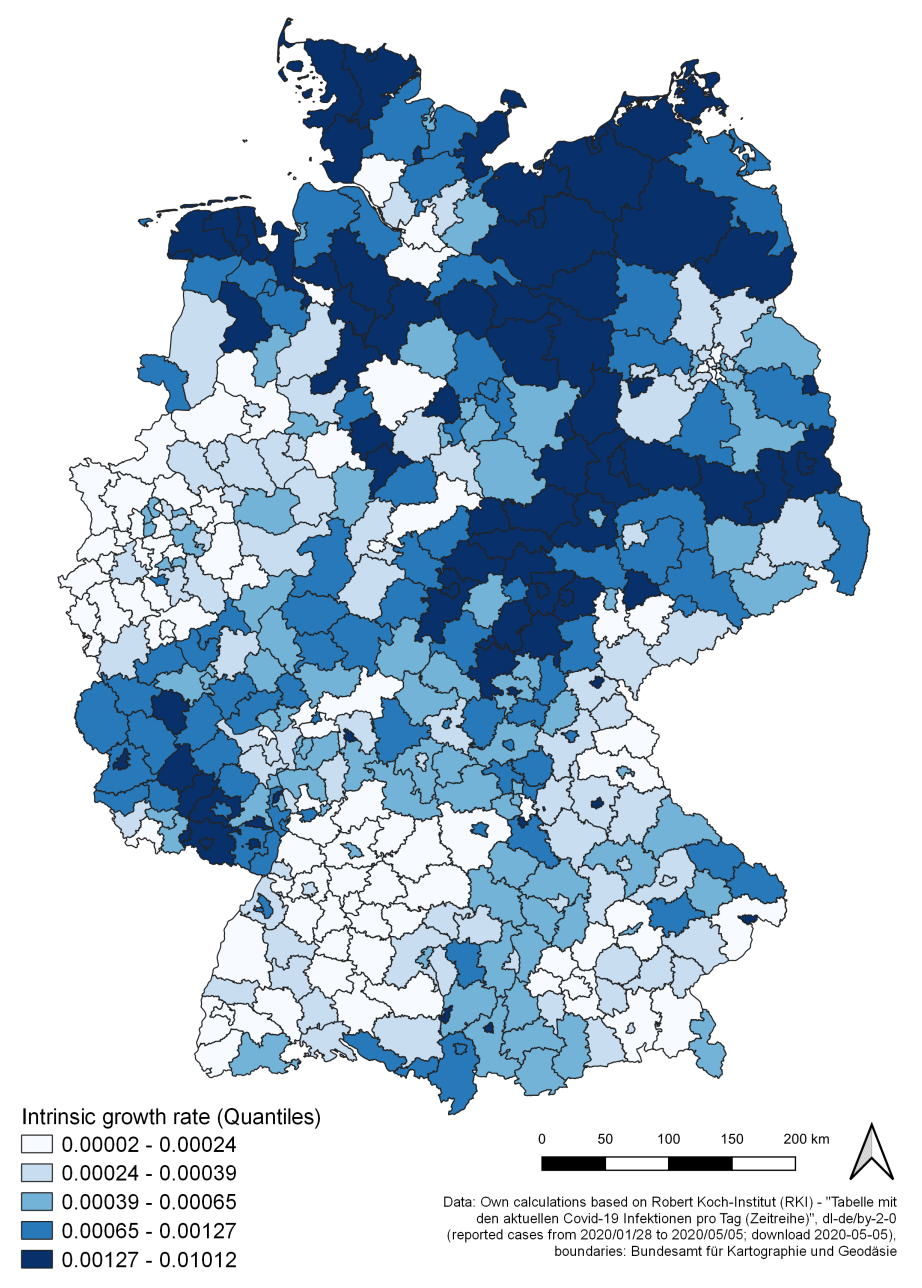

Figure 5: Intrinsic growth rate by county

the curve already flattened before the closing of schools and child day care centers (March 16-18, 2020). Six of them exceeded the peak of new infections even before March 13. This category refers to the appeals of chancellor Merkel and president Steinmeier on March 12. In 157 counties $(38.11 \%)$ with a population of 28.54 million people $(34.34 \%$ of the national population), the decrease of infections took place within the period of strict regulations towards social distancing and ban of gatherings.

The average time interval between the first estimated infection and the respective inflection point of the county is $\bar{x}=30.32$ [days]. However, the time until inflection point is characterized by a large variance $(S D=11.92)$, but this may be explained partially by the (de facto unknown) variance in the incubation period and the variance in the delay between onset of symptoms and reporting date.

In all counties, the inflection points lie between March 6 and April 18, 2020, which means a time period of 43 days between the first and the last flattening of a county's epidemic curve. The first regional decrease can be found in Heinsberg county (North Rhine Westphalia; 254,322 inhabitants), which was one of the first Corona "hotspots" in Germany. The estimated inflection point here took place at March 6, 2020, leading to a date of the first day after the inflection point of March 7. The latest estimated inflection point (April 18, 2020) took place in Steinburg county (Schleswig-Holstein; 131,347 inhabitants).

As Figure 8 shows, the intrinsic growth rates, which indicate an average growth level over time, and inflection points of the logistic models are linked. Growth speed declines 


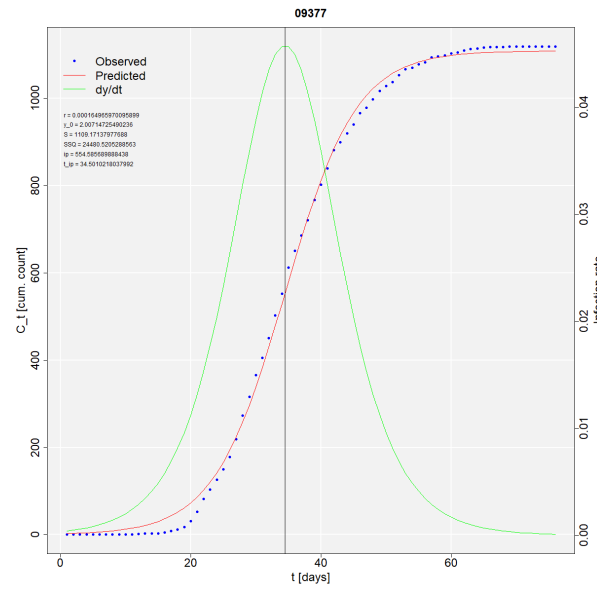

(a) Tirschenreuth county (Bavaria)

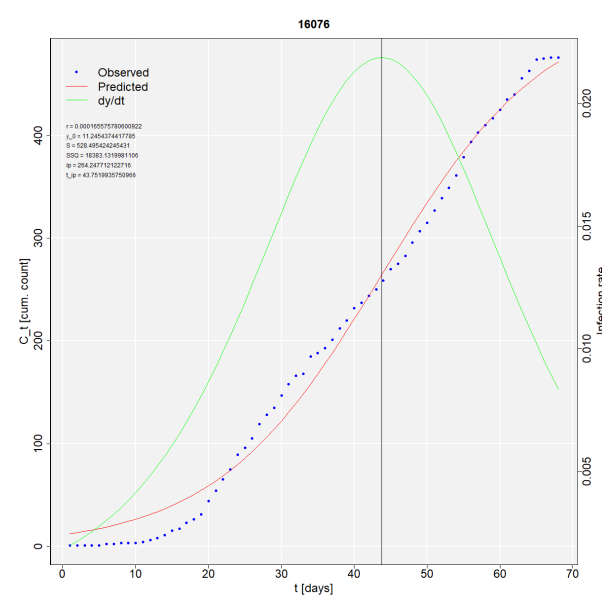

(c) Greiz county (Thuringia)

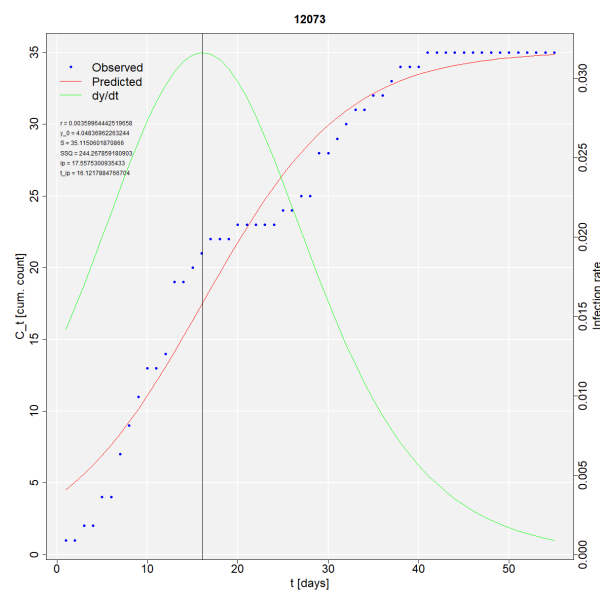

(e) Uckermark county (Brandenburg)

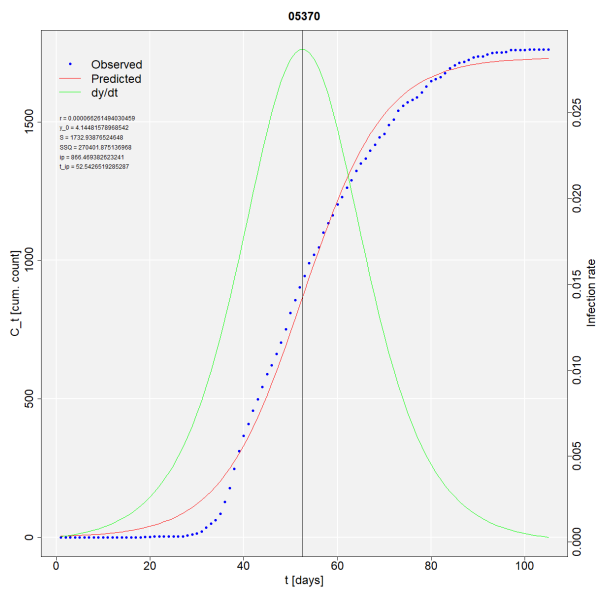

(b) Heinsberg county (North Rhine Westphalia)

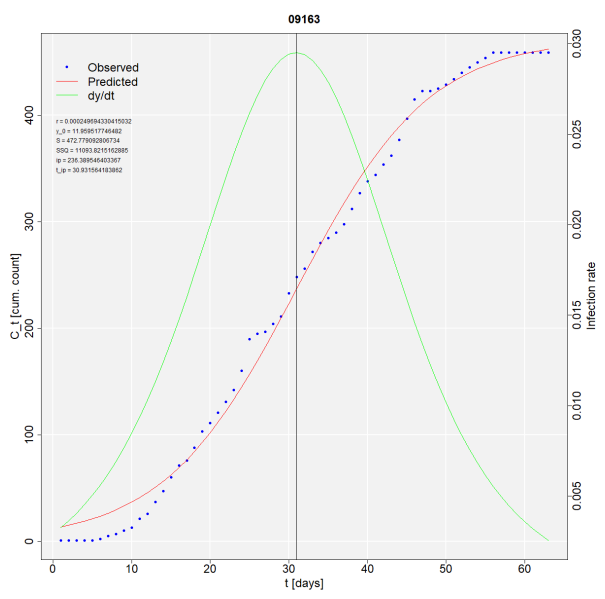

(d) Rosenheim county (Bavaria)

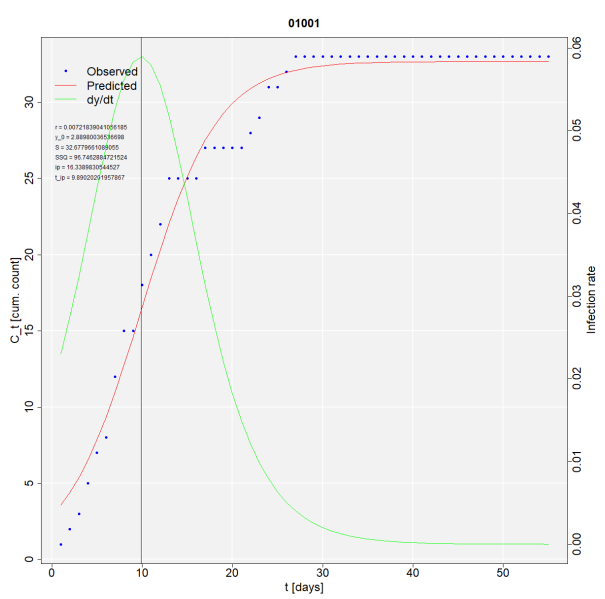

(f) Flensburg (Schleswig-Holstein)

Figure 6: Cumulative SARS-CoV-2 infections (based on estimated dates of infection) and estimated logistic growth models (including infection rate and inflection point) in six German counties

Source: own illustration. Data source: own calculations based on RKI (2020b) 


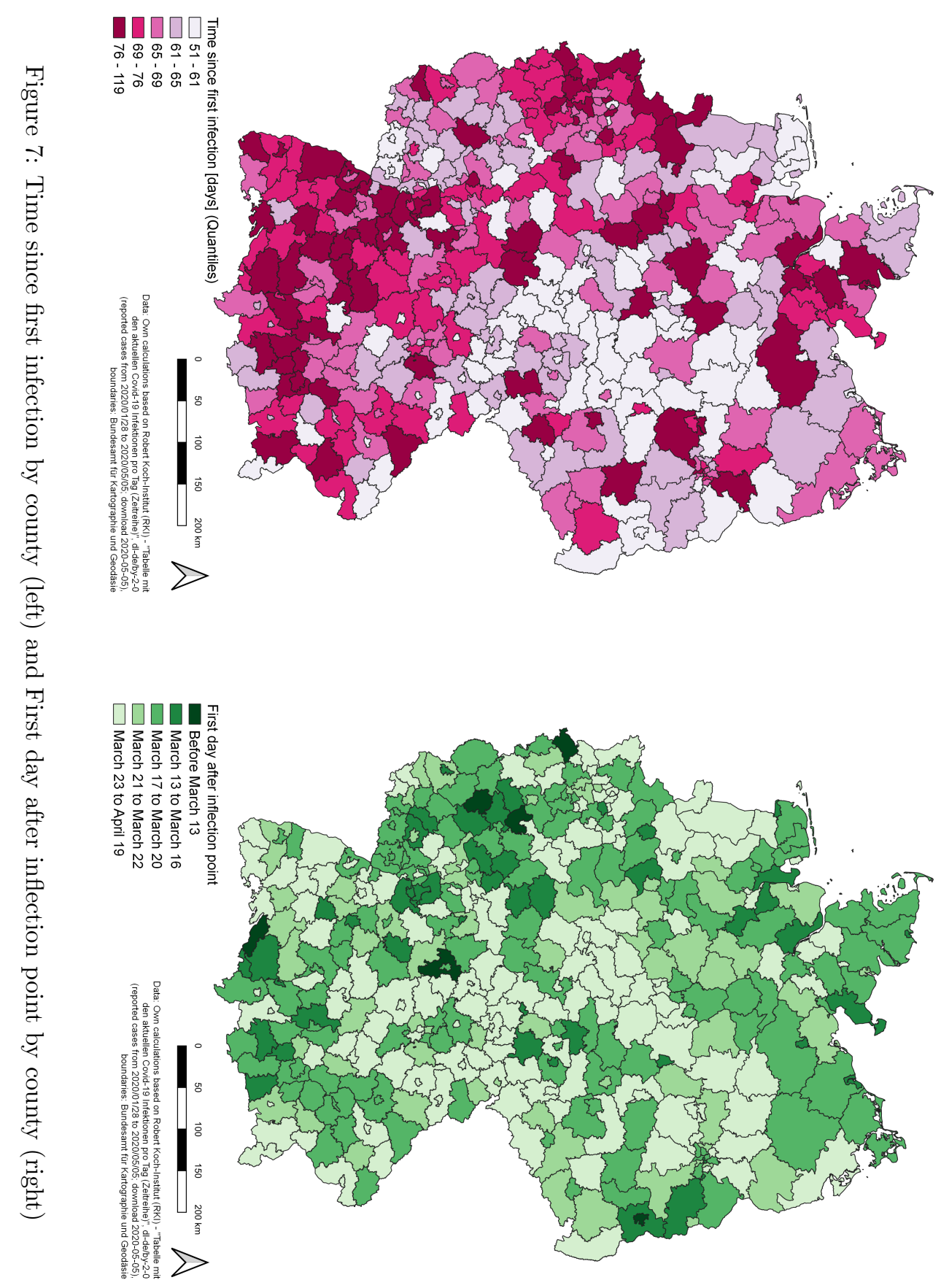




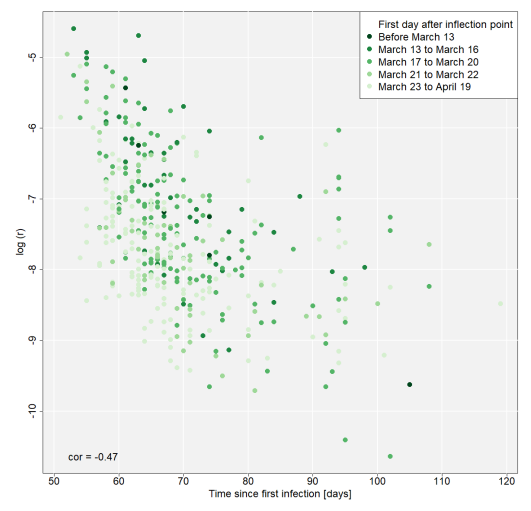

Figure 8: Growth rate and first day after inflection point vs. time Source: own illustration. Data source: own calculations based on RKI (2020b)

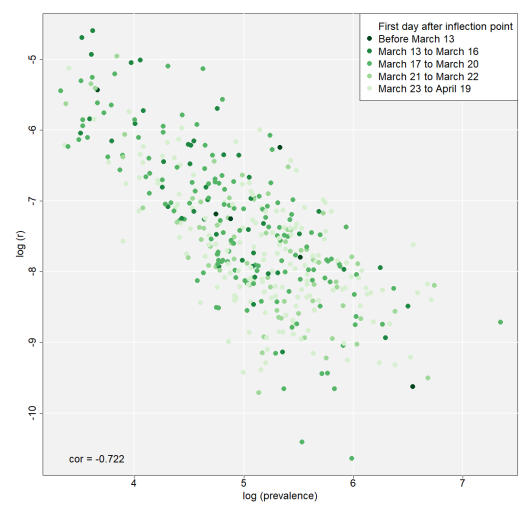

Figure 9: Growth rate and first day after inflection point vs. prevalence Source: own illustration. Data source: own calculations based on RKI (2020b)

over time (see also Figures 5 and 8), more precisely, it declines in line with the time the disease is present in the regarded county (Pearson correlation coefficient of -0.47 , $p<0.001)$. The longer the time between inflection point and now, the lower the growth speed, and vice versa. This process takes place over all German counties with a time delay depending on the first occurrence of the disease. As shown in Figure 9, there is also a negative correlation between regional prevalence and growth rate (Pearson correlation coefficient of $-0.722, p<0.001)$. These relationships, which are closely linked to the chronology of an infectious disease spread and the characteristics of the logistic growth model, respectively, are included into the regression models as control variables.

\subsection{Regression models for intrinsic growth rates and mortality}

The variables of most interest used within the models are mapped in Figures 10a (prevalence, $P R V$ ), 10b (mortality, $M R T$ ) and 11a (share of infected individuals of age $\geq 60$, POPS65). Additionally, Figure 11b shows the current case fatality rate on the county level. Tables 7 and 8 show the estimation results for the OLS regression models explaining the intrinsic growth rates and the mortality, respectively, both transformed via natural logarithm. Table 9 displays the Moran's I-statistic for the dependent variables of the two models. Tables 10 and 11 show the estimation results for the spatial lag models.

In all of the OLS models, no variable exceeded the critical value of $V I F \geq 5$. For the prediction of the intrinsic growth rate, two model variants were estimated without and with the state dummy variables (Table 7 ). From the aspect of explained variance, the second OLS model provides a better fit $\left(R^{2}=0.731\right.$ and Adj. $R^{2}=0.723$, respectively) 


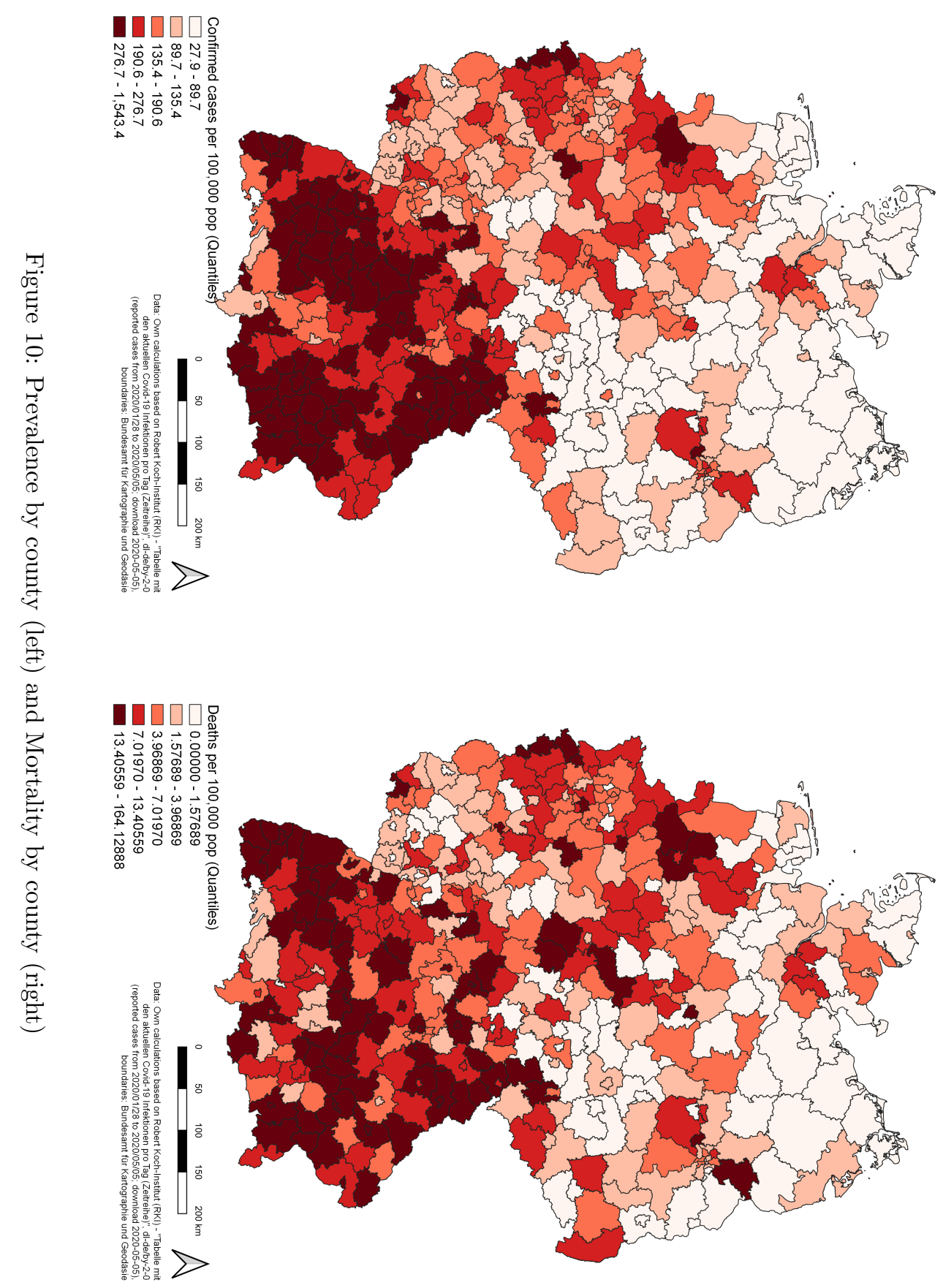



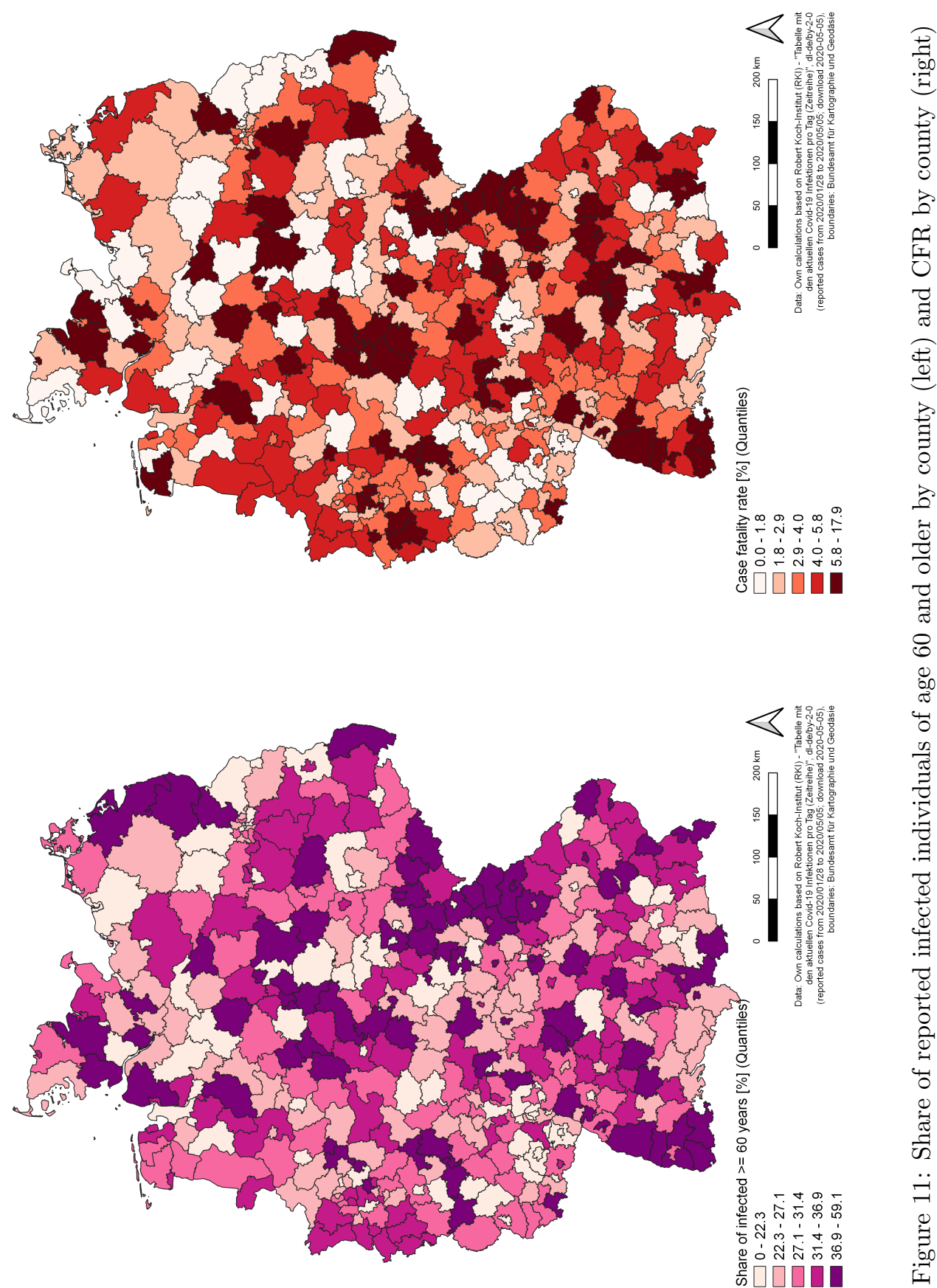
Table 7: Estimation results for the growth rate model (OLS)

\begin{tabular}{|c|c|c|}
\hline & \multicolumn{2}{|c|}{ Dependent variable: $\ln (r)$} \\
\hline & $(1)$ & $(2)$ \\
\hline $\ln (\mathrm{POPDENS})$ & $\begin{array}{c}-0.177^{* * *} \\
(0.028)\end{array}$ & $\begin{array}{c}-0.102^{* * *} \\
(0.027)\end{array}$ \\
\hline $\ln (\mathrm{POPS65})$ & $\begin{array}{c}0.830^{* * *} \\
(0.284)\end{array}$ & $\begin{array}{c}1.165^{* * *} \\
(0.269)\end{array}$ \\
\hline $\ln (\mathrm{CMI})$ & $\begin{array}{c}0.607^{* * *} \\
(0.091)\end{array}$ & $\begin{array}{c}0.420^{* * *} \\
(0.087)\end{array}$ \\
\hline $\ln (\mathrm{TOUR})$ & $\begin{array}{c}0.146^{* * *} \\
(0.042)\end{array}$ & $\begin{array}{c}0.035 \\
(0.041)\end{array}$ \\
\hline EAST & $\begin{array}{l}-0.087 \\
(0.091)\end{array}$ & $\begin{array}{l}-0.045 \\
(0.089)\end{array}$ \\
\hline $\mathrm{BV}$ & & $\begin{array}{c}0.473^{* * *} \\
(0.091)\end{array}$ \\
\hline SL & & $\begin{array}{c}0.118 \\
(0.231)\end{array}$ \\
\hline SX & & $\begin{array}{c}-0.580^{* * *} \\
(0.168)\end{array}$ \\
\hline NRW & & $\begin{array}{c}-0.428^{* * *} \\
(0.097)\end{array}$ \\
\hline $\mathrm{BW}$ & & $\begin{array}{c}0.011 \\
(0.108)\end{array}$ \\
\hline $\ln (\mathrm{PRV})$ & $\begin{array}{c}-0.911^{* * *} \\
(0.049)\end{array}$ & $\begin{array}{c}-1.039^{* * *} \\
(0.056)\end{array}$ \\
\hline DAYS & $\begin{array}{c}-0.019^{* * *} \\
(0.003)\end{array}$ & $\begin{array}{c}-0.014^{* * *} \\
(0.003)\end{array}$ \\
\hline Constant & $\begin{array}{c}-3.660^{* * *} \\
(1.144)\end{array}$ & $\begin{array}{c}-4.214^{* * *} \\
(1.079)\end{array}$ \\
\hline Observations & 412 & 412 \\
\hline $\mathrm{R}^{2}$ & 0.678 & 0.731 \\
\hline Adjusted $\mathrm{R}^{2}$ & 0.672 & 0.723 \\
\hline Residual Std. Error & 0.587 & 0.540 \\
\hline Degrees of Freedom & 404 & 399 \\
\hline F Statistic & $121.278^{* * *}$ & $90.307^{* * *}$ \\
\hline Degrees of Freedom & $7 ; 404$ & $12 ; 399$ \\
\hline
\end{tabular}

Note: ${ }^{*} \mathrm{p}<0.1 ;{ }^{* *} \mathrm{p}<0.05 ;{ }^{* * *} \mathrm{p}<0.01$

compared to the first $\left(R^{2}=0.678\right.$ and Adj. $R^{2}=0.672$, respectively), thus, the second model is to be preferred for interpretation. Different than expected, population density $(P O P D E N S)$ does not affect growth rate positively. A $1 \%$ increase of population density decreases the growth rate by $0.1 \%$. Also the demographic indicator (POPS65) is correlated with growth contrary to expectations: An increase of $1 \%$ in the share of inhabitants of age $\geq 65$ increases the growth rate by $1.2 \%$. As expected, the intensity of commuting $(C M I)$ has a significant positive effect on the intrinsic growth rate: An increase of commuting intensity by $1 \%$ increases the growth rate by $0.4 \%$. Tourist density (TOUR) is only significant in the first model. On average, the intrinsic growth rate is significantly higher in Bavarian counties (dummy variable $B V$ ), and significantly lower in Saxony and North Rhine-Westphalian counties ( $S L$ and $S X$, respectively). The coefficients for Baden-Wuerttemberg $(B W)$ and Saarland $(S L)$ are not significant, which means that no significant deviation from the average growth rate is found for counties in these German states. The EAST dummy is insignificant in both models. Considering the necessary control variables, the current prevalence $(P R V)$ and time $(D A Y S)$ decelerate the growth of infections significantly. The former has a nearly proportional impact: An increase of prevalence equal to $1 \%$ decreases the intrinsic growth rate by $1.04 \%$. For each day 
SARS-CoV-2/COVID-19 is present in the county, the growth speed declines on average by $1.4 \%$. Here, one has to keep in mind that these relationships are reciprocal and represent the mandatory decline of susceptible individuals over time.

For the prediction of mortality $(M R T)$, the growth rate $(r)$ and the state dummy variables $(B V, S L, S X$ and $N R W)$ are entered into the model analyis successively, resulting in the three models shown in Table 8. When comparing models 1 and 2 , adding the growth rate as independent variable increases the explained variance substantially (Adj. $R^{2}=0.219$ and 0.367 , respectively). The third model provides the best fit, adjusted for the number of explanatory variables (Adj. $\left.R^{2}=0.383\right)$. No significant influence can be found for the spatial (POPDENS), demographic (POPS65), mobility (PI and TOUR), and air pollution variables (PM10 and NO2). Life expectancy ( $L E X P)$ and the dummy for East German counties $(E A S T)$ are only significant in the first model. However, the share of infected people of age $\geq 60$ (INFS60) significantly increases the regional mortality: An increase in the share of people of the "risk group" in all infected by $1 \%$ increases the mortality by approx. $0.5 \%$. The only significant state-specific effect is found for Bavaria: The mortality in Bavarian counties is higher than in the counties of other states. Furthermore, a two-sample t-test reveals that Bavarian counties have a significantly higher share of infected belonging to the risk group $(\bar{x}=31.11 \%)$ compared to the remaining states $(\bar{x}=29.28 \%)$, with a difference of 1.83 percentage points $(p=0.054)$. The reciprocal relationship between mortality and growth rate is also significant.

As expected, spatial autocorrelation can be detected among the dependent variables. The Moran's I-statistic for both regional growth rate and mortality ( 0.49 and 0.16 , respectively) is significant (see Table 9). Consequently, the OLS estimations are expected to be biased. Therefore, we apply a spatial lag model in the next step.

With respect to the spatial lag model for regional growth rates (Table 10), the $\rho$ parameter in both model variants is significant ( $\rho=0.158$ and $\rho=0.095$, respectively), which indicates a significant spatial lag effect. However, when comparing the second spatial lag model (with $A I C=674.96$, which is superior to model 1 with $A I C=733.37$ ) to the second OLS model (see Table 7), there are only negligible differences in the parameter estimates and significance levels: The same independent variables are found to be significantly correlated with growth rates. They also have the same sign, which indicates the same direction of influence. Intrinsic growth rates on the county level are predicted by population density (approx. -0.9), population share of 65 and older (approx. 1.1), commuting intensity (approx. 0.4), and state-specific dummy variables (Bavaria: approx. 0.5, Saxony: approx. -0.5, North Rhine Westphalia: approx. -0.4) as well as the control variables (Prevalence: approx. -1.0 and time since first infection: approx. -0.01).

The same conclusion can be drawn with respect to the spatial lag models for mortality (Table 11), when comparing them to the OLS models (Table 8). The spatial lag effect is only significant in the first model $(\rho=0.165)$ but not in models $2(\rho=0.042)$ and 3 $(\rho=-0.044)$. Regional mortality is significantly influenced by the share of infected people of age $\geq 60$ (approx. 0.5) and the dummy variable for Bavarian counties (approx. 1.2) as well as correlated with regional growth rates (approx. -1.6). As spatial autocorrelation was also detected for the regional growth rate, which is an independent variable in the mortality models, a further robustness check of the estimations is necessary: Table 12 shows the results for the second and third mortality model in a spatial Durbin model, which incorporates a spatial lag effect for both the dependent variable $(\rho)$ and the regional growth rate $(\operatorname{lag} \ln (r))$. The lag effect of $\ln (r)$ is statistically significant, but the other results remain qualitatively the same (share of infected people of age $\geq 60$ : approx. 0.5; dummy variable for Bavarian counties: approx. 1).

With respect to the regression models for regional growth and mortality, the results of the OLS estimations were confirmed by those from the models allowing for spatial autocorrelation. Although there is obvious spatial autocorrelation (which can be explained plausibly by interregional transmission of the infectious disease), both OLS and spatial regression models show nearly the same results with respect to strength and direction of correlations. From the spatial statistic point of view, this can be explained with the incorporated independent variables as regional differences in both growth rate and mortality are predicted entirely by the interregional variation in causal factors. 
Table 8: Estimation results for the mortality model (OLS)

\begin{tabular}{|c|c|c|c|}
\hline & \multicolumn{3}{|c|}{ Dependent variable: $\ln (\mathrm{MRT}+0.0001)$} \\
\hline & $(1)$ & $(2)$ & $(3)$ \\
\hline \multirow[t]{2}{*}{$\ln (\mathrm{POPDENS})$} & -0.060 & $-0.268^{* *}$ & -0.148 \\
\hline & $(0.132)$ & $(0.121)$ & $(0.124)$ \\
\hline \multirow[t]{2}{*}{$\ln ($ POPS65) } & -0.738 & 0.883 & 1.730 \\
\hline & $(1.316)$ & $(1.196)$ & $(1.230)$ \\
\hline \multirow[t]{2}{*}{$\ln (\mathrm{CMI})$} & -0.627 & 0.397 & 0.025 \\
\hline & $(0.412)$ & $(0.385)$ & $(0.396)$ \\
\hline \multirow[t]{2}{*}{$\ln (\mathrm{TOUR})$} & -0.265 & 0.066 & -0.081 \\
\hline & $(0.188)$ & $(0.173)$ & $(0.178)$ \\
\hline \multirow[t]{2}{*}{$\ln (\mathrm{LEXP})$} & $54.205^{* * *}$ & 11.409 & 12.349 \\
\hline & $(12.259)$ & $(11.877)$ & $(12.556)$ \\
\hline \multirow[t]{2}{*}{$\ln (\mathrm{PM} 10)$} & 0.053 & -0.226 & -0.200 \\
\hline & $(0.716)$ & $(0.645)$ & $(0.653)$ \\
\hline \multirow[t]{2}{*}{$\ln (\mathrm{NO} 2)$} & 0.428 & 0.178 & 0.213 \\
\hline & $(0.287)$ & $(0.259)$ & $(0.259)$ \\
\hline \multirow[t]{2}{*}{$\ln (\mathrm{INFS60+0.0001)}$} & $0.618^{* * *}$ & $0.459^{* * *}$ & $0.462^{* * *}$ \\
\hline & $(0.104)$ & $(0.095)$ & $(0.094)$ \\
\hline \multirow[t]{2}{*}{ EAST } & $-0.980^{* *}$ & -0.496 & -0.148 \\
\hline & $(0.395)$ & $(0.359)$ & $(0.385)$ \\
\hline \multirow[t]{2}{*}{ BV } & & & $1.110^{* * *}$ \\
\hline & & & $(0.334)$ \\
\hline \multirow[t]{2}{*}{$\mathrm{SL}$} & & & 0.800 \\
\hline & & & $(0.983)$ \\
\hline \multirow[t]{2}{*}{ SX } & & & -0.909 \\
\hline & & & $(0.738)$ \\
\hline \multirow[t]{2}{*}{ NRW } & & & -0.144 \\
\hline & & & $(0.433)$ \\
\hline \multirow[t]{2}{*}{ BW } & & & 0.193 \\
\hline & & & $(0.465)$ \\
\hline \multirow[t]{2}{*}{ DAYS } & 0.017 & -0.014 & -0.011 \\
\hline & $(0.013)$ & $(0.012)$ & $(0.012)$ \\
\hline \multirow[t]{2}{*}{$\ln (r)$} & & $-1.570^{* * *}$ & $-1.535^{* * *}$ \\
\hline & & $(0.161)$ & $(0.171)$ \\
\hline \multirow[t]{2}{*}{ Constant } & $-237.384^{* * *}$ & -62.529 & -69.684 \\
\hline & $(55.406)$ & $(53.006)$ & $(55.923)$ \\
\hline Observations & 412 & 412 & 412 \\
\hline $\mathrm{R}^{2}$ & 0.238 & 0.384 & 0.407 \\
\hline Adjusted $\mathrm{R}^{2}$ & 0.219 & 0.367 & 0.383 \\
\hline Residual Std. Error & 2.596 & 2.336 & 2.308 \\
\hline Degrees of Freedom & 401 & 400 & 395 \\
\hline F Statistic & $12.525^{* * *}$ & $22.679^{* * *}$ & $16.916^{* * *}$ \\
\hline Degrees of Freedom & $10 ; 401$ & $11 ; 400$ & $16 ; 395$ \\
\hline
\end{tabular}

Note: ${ }^{*} \mathrm{p}<0.1 ;{ }^{* *} \mathrm{p}<0.05 ;{ }^{* * *} \mathrm{p}<0.01$

Table 9: Moran's I-statistic for intrinsic growth rates and mortality (Weighting matrix: all adjacent counties)

\begin{tabular}{lcccc}
\hline Indicator & Moran's I & Expectation & Variance & Standard deviate \\
\hline $\ln (r)$ & $0.4856^{* * *}$ & -0.0024 & 0.0011 & 14.738 \\
$\ln (\mathrm{MRT}+0.0001)$ & $0.1635^{* * *}$ & -0.0024 & 0.0011 & 5.0555 \\
\hline
\end{tabular}

Note: ${ }^{*} \mathrm{p}<0.1 ;{ }^{* *} \mathrm{p}<0.05 ;{ }^{* * *} \mathrm{p}<0.01$

Source: own calculation. 
Table 10: Estimation results for the growth rate model (spatial lag model)

\begin{tabular}{|c|c|c|}
\hline & \multicolumn{2}{|c|}{ Dependent variable: $\ln (r)$} \\
\hline & $(1)$ & $(2)$ \\
\hline $\ln (\mathrm{POPDENS})$ & $\begin{array}{c}-0.151^{* * *} \\
(0.027)\end{array}$ & $\begin{array}{c}-0.089^{* * *} \\
(0.027)\end{array}$ \\
\hline $\ln ($ POPS65) & $\begin{array}{c}0.755^{* * *} \\
(0.279)\end{array}$ & $\begin{array}{c}1.119^{* * *} \\
(0.265)\end{array}$ \\
\hline $\ln (\mathrm{CMI})$ & $\begin{array}{c}0.561^{* * *} \\
(0.092)\end{array}$ & $\begin{array}{c}0.402^{* * *} \\
(0.087)\end{array}$ \\
\hline $\ln ($ TOUR $)$ & $\begin{array}{c}0.121^{* * *} \\
(0.041)\end{array}$ & $\begin{array}{c}0.024 \\
(0.041)\end{array}$ \\
\hline EAST & $\begin{array}{c}-0.148^{*} \\
(0.089)\end{array}$ & $\begin{array}{l}-0.076 \\
(0.089)\end{array}$ \\
\hline BV & & $\begin{array}{c}0.498^{* * *} \\
(0.090)\end{array}$ \\
\hline SL & & $\begin{array}{c}0.096 \\
(0.226)\end{array}$ \\
\hline SX & & $\begin{array}{c}-0.538^{* * *} \\
(0.166)\end{array}$ \\
\hline NRW & & $\begin{array}{c}-0.368^{* * *} \\
(0.100)\end{array}$ \\
\hline $\mathrm{BW}$ & & $\begin{array}{c}0.073 \\
(0.110)\end{array}$ \\
\hline $\ln (\mathrm{PRV})$ & $\begin{array}{c}-0.827^{* * *} \\
(0.058)\end{array}$ & $\begin{array}{c}-1.002^{* * *} \\
(0.060)\end{array}$ \\
\hline DAYS & $\begin{array}{c}-0.018^{* * *} \\
(0.003)\end{array}$ & $\begin{array}{c}-0.014^{* * *} \\
(0.003)\end{array}$ \\
\hline Constant & $\begin{array}{c}-2.677^{* *} \\
(1.159)\end{array}$ & $\begin{array}{c}-3.562^{\text {*** }} \\
(1.110)\end{array}$ \\
\hline$\rho$ & $\begin{array}{c}0.158^{* * *} \\
(0.049)\end{array}$ & $\begin{array}{c}0.095^{*} \\
(0.050)\end{array}$ \\
\hline Observations & 412 & 412 \\
\hline Log Likelihood & -356.682 & -322.481 \\
\hline$\sigma^{2}$ & 0.329 & 0.280 \\
\hline Akaike Inf. Crit. & 733.365 & 674.962 \\
\hline LR Test $(\mathrm{df}=1)$ & $9.283^{* * *}$ & $3.193^{*}$ \\
\hline Wald Test $(\mathrm{df}=1)$ & $10.325^{* * *}$ & $3.608^{*}$ \\
\hline
\end{tabular}

Note: ${ }^{*} \mathrm{p}<0.1 ;{ }^{* *} \mathrm{p}<0.05 ;{ }^{* * *} \mathrm{p}<0.01$ Source: own calculation. 
Table 11: Estimation results for the mortality model (spatial lag model)

\begin{tabular}{|c|c|c|c|}
\hline & \multicolumn{3}{|c|}{ Dependent variable: $\ln (\mathrm{MRT}+0.0001)$} \\
\hline & $(1)$ & $(2)$ & $(3)$ \\
\hline \multirow[t]{2}{*}{$\ln (\mathrm{POPDENS})$} & -0.085 & $-0.272^{* *}$ & -0.138 \\
\hline & $(0.129)$ & $(0.119)$ & $(0.121)$ \\
\hline \multirow[t]{2}{*}{$\ln (\mathrm{POPS65})$} & -0.500 & 0.921 & 1.731 \\
\hline & $(1.289)$ & $(1.178)$ & $(1.204)$ \\
\hline \multirow[t]{2}{*}{$\ln (\mathrm{CMI})$} & -0.586 & 0.394 & 0.013 \\
\hline & $(0.403)$ & $(0.379)$ & $(0.387)$ \\
\hline \multirow[t]{2}{*}{$\ln (\mathrm{TOUR})$} & -0.250 & 0.066 & -0.086 \\
\hline & $(0.184)$ & $(0.170)$ & $(0.175)$ \\
\hline \multirow[t]{2}{*}{$\ln (\mathrm{LEXP})$} & $51.311^{* * *}$ & 11.262 & 12.321 \\
\hline & $(12.101)$ & $(11.713)$ & $(12.288)$ \\
\hline \multirow[t]{2}{*}{$\ln (\mathrm{PM} 10)$} & 0.197 & -0.186 & -0.224 \\
\hline & $(0.700)$ & $(0.637)$ & $(0.639)$ \\
\hline \multirow[t]{2}{*}{$\ln (\mathrm{NO} 2)$} & 0.397 & 0.174 & 0.215 \\
\hline & $(0.280)$ & $(0.255)$ & $(0.254)$ \\
\hline \multirow[t]{2}{*}{$\ln (\mathrm{INFS60+0.0001)}$} & $0.614^{* * *}$ & $0.460^{* * *}$ & $0.461^{* * *}$ \\
\hline & $(0.102)$ & $(0.094)$ & $(0.092)$ \\
\hline \multirow[t]{2}{*}{ EAST } & $-0.764^{*}$ & -0.448 & -0.180 \\
\hline & $(0.399)$ & $(0.365)$ & $(0.382)$ \\
\hline \multirow[t]{2}{*}{ BV } & & & $1.185^{* * *}$ \\
\hline & & & $(0.349)$ \\
\hline \multirow[t]{2}{*}{$\mathrm{SL}$} & & & 0.800 \\
\hline & & & $(0.962)$ \\
\hline \multirow[t]{2}{*}{ SX } & & & -0.914 \\
\hline & & & $(0.722)$ \\
\hline \multirow[t]{2}{*}{ NRW } & & & -0.119 \\
\hline & & & $(0.426)$ \\
\hline \multirow[t]{2}{*}{ BW } & & & 0.245 \\
\hline & & & $(0.466)$ \\
\hline \multirow[t]{2}{*}{ DAYS } & 0.017 & -0.013 & -0.011 \\
\hline & $(0.012)$ & $(0.012)$ & $(0.012)$ \\
\hline \multirow[t]{2}{*}{$\ln (\mathrm{r})$} & & $-1.549^{* * *}$ & $-1.550^{* * *}$ \\
\hline & & $(0.162)$ & $(0.168)$ \\
\hline \multirow[t]{2}{*}{ Constant } & $-225.876^{* * *}$ & -62.008 & -69.584 \\
\hline & $(54.613)$ & $(52.268)$ & $(54.731)$ \\
\hline \multirow[t]{2}{*}{$\rho$} & $0.165^{* *}$ & 0.042 & -0.044 \\
\hline & $(0.064)$ & $(0.062)$ & $(0.065)$ \\
\hline Observations & 412 & 412 & 412 \\
\hline Log Likelihood & -969.231 & -927.965 & -920.308 \\
\hline$\sigma^{2}$ & 6.435 & 5.293 & 5.100 \\
\hline Akaike Inf. Crit. & $1,964.461$ & $1,883.930$ & $1,878.615$ \\
\hline Wald Test $(\mathrm{df}=1)$ & $6.714^{* * *}$ & 0.449 & 0.454 \\
\hline $\mathrm{LR}$ Test $(\mathrm{df}=1)$ & $5.551^{* *}$ & 0.378 & 0.365 \\
\hline
\end{tabular}

Note: ${ }^{*} \mathrm{p}<0.1 ;{ }^{* *} \mathrm{p}<0.05 ;{ }^{* * *} \mathrm{p}<0.01$ Source: own calculation. 
Table 12: Estimation results for the mortality model (spatial Durbin model)

\begin{tabular}{|c|c|c|}
\hline & \multicolumn{2}{|c|}{ Dependent variable: $\ln (\mathrm{MRT}+0.0001)$} \\
\hline ln (POPDENS) & $\begin{array}{c}-0.328^{* * *} \\
(0.121)\end{array}$ & $\begin{array}{l}-0.202 \\
(0.124)\end{array}$ \\
\hline $\ln (\mathrm{POPS65})$ & $\begin{array}{c}0.984 \\
(1.173)\end{array}$ & $\begin{array}{c}1.816 \\
(1.195)\end{array}$ \\
\hline $\ln (\mathrm{CMI})$ & $\begin{array}{c}0.476 \\
(0.379)\end{array}$ & $\begin{array}{c}0.092 \\
(0.386)\end{array}$ \\
\hline $\ln (\mathrm{TOUR})$ & $\begin{array}{c}0.146 \\
(0.172)\end{array}$ & $\begin{array}{l}-0.012 \\
(0.176)\end{array}$ \\
\hline $\ln (\mathrm{LEXP})$ & $\begin{array}{c}6.216 \\
(11.834)\end{array}$ & $\begin{array}{c}7.535 \\
(12.352)\end{array}$ \\
\hline $\ln (\mathrm{PM} 10)$ & $\begin{array}{c}-0.189 \\
(0.633)\end{array}$ & $\begin{array}{l}-0.358 \\
(0.636)\end{array}$ \\
\hline $\ln (\mathrm{NO} 2)$ & $\begin{array}{c}0.160 \\
(0.254)\end{array}$ & $\begin{array}{c}0.238 \\
(0.252)\end{array}$ \\
\hline $\ln ($ INFS60+0.0001) & $\begin{array}{c}0.467^{* * *} \\
(0.093)\end{array}$ & $\begin{array}{c}0.465^{* * *} \\
(0.092)\end{array}$ \\
\hline EAST & $\begin{array}{c}-0.236 \\
(0.373)\end{array}$ & $\begin{array}{c}0.022 \\
(0.388)\end{array}$ \\
\hline $\mathrm{BV}$ & & $\begin{array}{c}0.980^{* * *} \\
(0.357)\end{array}$ \\
\hline $\mathrm{SL}$ & & $\begin{array}{c}0.829 \\
(0.955)\end{array}$ \\
\hline SX & & $\begin{array}{l}-1.131 \\
(0.722)\end{array}$ \\
\hline NRW & & $\begin{array}{c}-0.474 \\
(0.450)\end{array}$ \\
\hline $\mathrm{BW}$ & & $\begin{array}{c}-0.139 \\
(0.489)\end{array}$ \\
\hline DAYS & $\begin{array}{l}-0.013 \\
(0.012)\end{array}$ & $\begin{array}{l}-0.009 \\
(0.011)\end{array}$ \\
\hline $\ln (r)$ & $\begin{array}{c}-1.422^{* * *} \\
(0.172)\end{array}$ & $\begin{array}{c}-1.456^{* * *} \\
(0.172)\end{array}$ \\
\hline $\operatorname{lag} \ln (r)$ & $\begin{array}{c}-0.555^{* *} \\
(0.254)\end{array}$ & $\begin{array}{c}-0.634^{* *} \\
(0.278)\end{array}$ \\
\hline Constant & $\begin{array}{l}-43.482 \\
(52.507)\end{array}$ & $\begin{array}{l}-52.706 \\
(54.744)\end{array}$ \\
\hline$\rho$ & $\begin{array}{l}-0.033 \\
(0.070)\end{array}$ & $\begin{array}{l}-0.116 \\
(0.072)\end{array}$ \\
\hline Observations & 412 & 412 \\
\hline Log Likelihood & -925.583 & -917.677 \\
\hline$\sigma^{2}$ & 5.233 & 5.025 \\
\hline Akaike Inf. Crit. & $1,881.167$ & $1,875.355$ \\
\hline Wald Test $(\mathrm{df}=1)$ & 0.223 & 2.607 \\
\hline LR Test $(\mathrm{df}=1)$ & 0.190 & 2.145 \\
\hline
\end{tabular}

Note: ${ }^{*} \mathrm{p}<0.1 ;{ }^{* *} \mathrm{p}<0.05 ;{ }^{* * *} \mathrm{p}<0.01$ Source: own calculation. 


\section{Discussion}

\subsection{Curve flattening in the context of nonpharmaceutical interventions}

Taking a look at the national level, the flattening of the epidemic curve in Germany occurred between three to six days before phase 3 of measures (as defined in this study) came into force. Due to this temporal mismatch, the decline of infections cannot be causally linked to the nationwide formal "lockdown" (including forced social distancing and ban of gatherings) of March 23. Note that the results for whole Germany, estimating the inflection point between March 17 and March 20, are rather conservative when compared with the RKI estimations. In the RKI nowcasting study, the peak of onset of symptoms (not infection time, which is not considered in the mentioned study) is found at March 18 and a stabilization of the reproduction number equal to $R=1$ at March 22 (an der Heiden, Hamouda 2020). Subtracting an average incubation period of five days from these dates, the peak of infections occured around March 13 and the reproduction number stabilizes approximately at March 17. An earlier RKI study (an der Heiden, Buchholz 2020) estimated the peaks between June and July, depending on the parameters of the scenarios.

The main focus of this analysis is on the regional level, which reveals a more differentiated picture. In all German counties the curves of infections clearly flattened within a time period of about six weeks from the first to the last county. On average, it took one month from the first infection to the inflection point of the epidemic curve. However, the regional trend change in infections is not in line with the governmental nonpharmaceutical interventions to contain the virus spread. In nearly two thirds of the German counties which account for two thirds of the German population, the flattening of the infection curve occured before the "lockdown" (measures of phase 3) came into force (March 23). One in eight counties experienced a decline of infections even before the closures of schools, child day care facilities and retail facilities, which is attributed to phase 2 of interventions in this study. Consequently, in a majority of counties, the regional decline of infections cannot be attributed to the formal "lockdown". In a minority of counties, also closures of educational and retail facilities (measures of phase 2) cannot have caused the decline. Keeping in mind that SARS-CoV-2 emerged at different times across the counties, it is at least questionable whether these measures primarily caused the flattening of the infection curve in the other counties. Furthermore, in a minority of counties, the regional trend change occurred several weeks (up to about four weeks) after the nonpharmaceutical interventions came into force. One might argue that there could be a time lag between the date of official enforcement of the regulations and the time they became effective in practice. However, this could only be conceivable for the contact ban but not for the closures of schools and other services as these infrastructures are either closed or not and, thus, can be potential places of virus transmission or not. Moreover, it seems unlikely that an intervention like a contact ban becomes effective only after several weeks and regionally differentiated.

Bringing together these aspects, regional curve flattening seems to have occurred independently from the governmental measures of phase 2 and 3. Instead, regional pandemic growth appears as a function of time, reaching the peak of infection rates with a time lag depending on the date the virus emerged.

The results presented here tend to support the findings in the study by Ben-Israel (2020) that curve flattening in the SARS-CoV-2/COVID-19 pandemic occurs with or without a strict "lockdown". However, neither this study nor the study by Ben-Israel (2020) provides explicit epidemiological, virological or other kinds of clarifications for this phenomenon. The further interpretation must be limited to a collection of explanation attempts, which are non-mutually exclusive. Some reasons for the decline of infections relate to other types of interventions both voluntary and mandatory are:

- First of all, it must be pointed out that the focus of this study is on regional pandemic growth in the context of the nonpharmaceutical interventions of phase 2 and 3 starting in mid March 2020, especially the "lockdown" from March 23. One has to keep in mind that some interventions against virus spread were already established in the first half of March (phase 1), e.g. the cancellation of large events or "ghost games" 
in soccer (see Table 1). These early measures could have contributed substantially to curve flattening, as the cancellation of events might have prevented people from being infected in the context of so-called super-spreading events, which play an enormous role during infectious disease spreads (Al-Tawfiq, Rodriguez-Morales 2020, Stein 2011). Many infections and death cases attributed to COVID-19 in the early phase of the pandemic in Germany can be traced back to super-spreading events in February and early March 2020, such as in Heinsberg or Tirschenreuth county (Tagesspiegel 2020b). Also, the domestic quarantine of infected persons (which is the default procedure in the case of infectious diseases) might have reduced new infections. In Heinsberg county, about 1,000 people were in domestic quarantine at the end of February 2020 (Tagesschau.de 2020c), which could explain the early curve flattening in this Corona "hotspot".

- Also media reports from China or Italy as well as appeals and recommendations from the government could have influenced people's behavior on a voluntary basis already in the first half of March 2020 (or even earlier), e.g. with respect to physical distancing, thorough and frequent hand washing, coughing and sneezing in the arm fold, or reducing mobility in general. Unfortunately, there is no explicit indicator of changes in the individual behavior. However, some other findings give a hint towards voluntary behavorial changes: Several surveys show a high degree of public awareness in Germany (and other countries) towards the SARS-CoV-2/COVID-19 threat already in February and the first half of March 2020 (Ipsos 2020, YouGov 2020). This increasing awareness might be reflected by more caution in daily life: The RKI has documented an "abrupt" decline of other infectious respiratory diseases with shorter incubation periods (such as influenza) in Germany since the 10th calendar week (March 2 to 8, 2020). This decline is regarded as "extremely unusual" (Buchholz et al. 2020). This reduction might be attributed to voluntary cautious behavior in the context of the public discussion towards SARS-CoV-2, as this decrease started before any public health intervention came into force (except for the quarantines of SARS-CoV-2-infected persons, see Table 1). Furthermore, the analysis of mobility patterns shows a decline of mobility in Germany, starting already in the first half of March 2020. Additionally, a strong correlation between (aggregated) mobility and the acceptance of social restrictions (obtained by surveys) was found: The higher the agreement with the statement "I think the current measures are too strict", the higher the increase in mobility (Covid-19 Mobility Project 2020a,b). All these phenomenons suggest voluntary behavior changes within the (German) population, which reduce the transmission of infectious diseases and preceded the "lockdown" by several weeks. Another indicator for an increased awareness in the (German) population - although not intended or desired - is the enormous tendency of hoarding groceries, which started in the second half of February 2020 (Rheinische Post online 2020).

- Additionally, one has to keep in mind the seasonal cycle of respiratory viral diseases: Influenza viruses and most cold viruses (including those from the family of Coronaviridae) mainly occur during the winter months due to changes in environmental parameters (e.g., temperature and humidity) and human behavior (more or fewer activities outside, whilst the risk of infection is, all other things being equal, lower outside) (Moriyama et al. 2020). Several virologists expressed cautious optimism towards the sensitivity of the SARS-CoV-2 virus to increasing temperature and ultraviolet radiation (Focus 2020). Model-based analyses from biogeography show that temperate warm and cold climates facilitate the virus spread, while arid and tropical climates are less favorable (Araujo, Naimi 2020). By consequence, there might have also been a decline of SARS-CoV-2 infections due to weather changes in early spring (mid-March).

Furthermore, there is another possible reason for curve flattening with or without a "lockdown", which is of epidemiological nature and related to the transmission process of SARS-CoV-2/COVID-19 in the context of immunization. Note that "immunity" may have different causes (e.g., antibodies due to previous infections, vaccination, immunological 
memory) and does not necessarily prevent individuals from being infected (in terms of an invasion of an individual's body) but leads to an effective response of the immune system and prevents the emergence of (severe) symptoms (Mak, Saunders 2006). At the beginning of the pandemic, two assumptions towards the role of immunization were stated: 1) Nobody is immune, which means that all individuals of the population belong to the group of susceptibles, 2) Without any interventions (e.g., vaccine, nonpharmaceutical interventions), herd immunity - a share of a population is immune, which provides protection to those who are not immune, causing the pandemic to slow down and stop - is achieved when about $70 \%$ of the population was infected (D'Souza, Dowdy 2020). This percentage share is commonly known as herd immunity threshold (HIT) and is, in its basic form, calculated based on the infection's basic reproduction number, $R_{0}$ : $H I T=1-1 / R_{0}$ (Fine et al. 2011). Early modeling studies focusing on the effect of nonpharmaceutical interventions are based on these (or similar) assumptions (an der Heiden, Buchholz 2020, Ferguson et al. 2020). However, there are some issues regarding the HIT for SARS-CoV-2/COVID-19 which need to be considered:

- In epidemiology, it is well known that disease transmission is mostly concentrated on a minor part of individuals causing a large majority of secondary infections: "In what became known as the 20/80 rule, a concept documented by observational and modeling studies and having profound implications for infection control, $20 \%$ of the individuals within any given population are thought to contribute at least $80 \%$ to the transmission potential of a pathogen, and many host-pathogen interactions were found to follow this empirical rule" (Stein 2011). Gomes et al. (2020) incorporate inter-individual variation in susceptibility and exposure to a SARS-CoV-2 infection into an epidemiological model (SEIR [susceptible-exposed-infectious-recovered] model). Depending on the assumptions on this overdispersion, the HIT of SARSCoV-2 reduces to $10-20 \%$. Thus, the achievement of herd immunity would require a considerably lower number of SARS-CoV-2 infections.

- Although the SARS-CoV-2 virus is highly infective, the "Heinsberg study" by Streeck et al. (2020) found a relatively low secondary infection risk (secondary attack rate, $\mathrm{SAR}$ ). Infected persons did not even infect other household members in the majority of cases. The authors conjecture that this could be due to a present immunity ( $\mathrm{T}$ helper cell immunity) not detected as positive in the test procedure. This kind of immunity is not to be confused with (temporal or everlasting) immunity due to antibodies against a specific virus but may be regarded as a functional immune memory. In a current virological study by Braun et al. (2020), 34\% of test persons who have never been infected with SARS-CoV-2 had relevant T helper cells because of earlier infections with other harmless Coronaviruses causing common colds. In a study by Grifoni et al. (2020), SARS-CoV-2-reactive T cells were detected in even $40 \%-60 \%$ of unexposed individuals. If this explanation proves correct, the absolute number of susceptible individuals would have been substantially lower already at the beginning of the pandemy. Other Coronaviruses are responsible for about 10-15\% of seasonal "common colds" (Padberg, Bauer 2006). Cross protection due to related virus strains has also been determined e.g. with respect to influenza viruses (Broberg et al. 2011).

- Considering the aforementioned aspects, we have to keep in mind that all data related to infections used here underestimate the real number of infected individuals in Germany as well as in nearly all countries where the Coronavirus emerged. Typically, at the beginning of the pandemic, only suspected cases with COVID19 symptoms were tested, leading to a heavy underestimation of infected people without symptoms (see Section 2.2). Several recent studies have tried to estimate the real prevalence of the virus and/or the infection fatality rate (IFR), including all infected cases rather than the confirmed (see Table 13). Estimated rates of unreported cases (estimate PRV/reported PRV) lie between 5 (Gangelt, Germany) and 50-85 (Santa Clara County, USA). Obviously, when estimated CFR values exceed the estimated IFR values by ten times or more, there must be a large number of unreported cases and the total number of infected individuals must be 
considerably higher than reported, respectively. The logical consequence is that there is a hidden decrease of the absolute number of susceptible individuals because of many infected persons without symptoms not knowing that they have been infected (and probably immunized) in the past. These individuals were not tested for the pathogen (SARS-CoV-2 virus) because they did not suffer from the disease (COVID-19). Quantifying the "dark figure" of SARS-CoV-2 infections by using representative sample-based tests on current infection as well as seroprevalence will be a challenge in the near future.

Of course, the present empirical results cannot prove or disprove the presence or absence of (herd) immunity. However, the number of infected individuals is obviously higher than reported (see Table 13), whilst the number of susceptibles could have been considerably smaller than expected already at the beginning of the pandemic. If a SARSCoV-2 infection leads to (lifelong or temporal) immunity (which is not yet clarified), the current level of immunity must be higher as well. Similar results were found in the UK: Stedman et al. (2020) also find decreasing infection rates $\left(R_{A D I R}\right)$ related to (reported and unreported) prevalence on the regional level (Upper Tier Local Authority areas) and conclude that "the only factor that could be related to the $R_{A D I R}$ in this analysis was the historic number of confirmed number infection/,000 population suggesting that some of the reduction in reported cases is due to the build-up of immunity due to larger numbers of historic cases in the population".

However, we have to keep in mind that even if herd immunity was achieved, this does not mean that no new infections occur. Furthermore, herd immunity implies a closed population, where there are too many immunized individuals to infect the remaining susceptibles. In reality, there are migratory and mobility flows between regions and nations (e.g., work-related commuting, tourism) and, thus, new infections may occur due to transmissions driven by spatial interactions. More precisely, a susceptible individual living in a given region with herd immunity might get infected when traveling to another region. Finally, there is a difference between infection and disease, whilst the infectiousness of asymptomatically infected individuals is not yet clarified, although they are regarded as much less likely to transmit the virus than infected with symptoms (World Health Organization 2020a).

\subsection{Determinants of regional growth and mortality}

Two regression models were estimated, with intrinsic growth rates (indicating the speed of pandemic growth) and mortality (indicating the severity of the disease) as dependent variables. For both variables, spatial autocorrelation was detected, which can be explained comprehensively by virus transmission across borders of nearby counties. However, both the OLS and the spatial regression models give qualitatively the same results.

With respect to the determinants of growth speed, two explanatory variables have a significant effect opposite to the expected: A slower disease spread is not due to lower population density. In contrast, intrinsic growth rates decrease with higher density values on the level of German counties. This could be explained with the validity of this indicator as it is questionable whether population density is a sufficient proxy for the amount and intensity of physical contacts between individuals. There is no empirical evidence that inhabitants living in larger and densely populated municipalities (such as large cities) have more social interactions than in people in rural areas (Mitterer 2013, Petermann 2001). There is also no dampening effect of virus spread by an older population on the county level. Instead, growth rates increase with the share of inhabitants of 65 years and older, although this age category covers the retired population. This result might be due to a bias in testing for SARS-CoV-2 infections: Most tests in the past were conducted on people with COVID-19 symptoms. As older people are more likely to have a severe course of the disease, these age groups are obviously overrepresented in the tested and confirmed cases (RKI 2020a). Differing from the expectations, no isolated effect of East German counties was found.

However, regional growth rates of infections are increased by inter-regional mobility, especially with respect to work-related commuting. This result is quite plausible and 
Table 13: Studys on unreported cases and/or IFR of SARS-CoV-2/COVID-19

\begin{tabular}{|c|c|c|c|c|c|c|c|}
\hline Study & Study area & $\mathrm{n}$ & $\begin{array}{l}\text { Time of } \\
\text { data } \\
\text { collection }\end{array}$ & $\begin{array}{c}\text { Est. } \\
\text { PRV [\%] } \\
\text { (CI95) }\end{array}$ & $\begin{array}{l}\text { Est.asymp- } \\
\text { tomatic } \\
\text { cases [\%] }\end{array}$ & $\begin{array}{l}\text { Est.PRV/ } \\
\text { reported } \\
\text { PRV }\end{array}$ & $\begin{array}{l}\text { Est. } \\
\text { IFR [\%] } \\
(\text { CI95) }\end{array}$ \\
\hline Bendavid et al. (2020) & $\begin{array}{l}\text { Santa Clara } \\
\text { county } \\
\text { (USA) }\end{array}$ & 3,324 & $04 / 2020$ & $\begin{array}{c}2.8 \\
(2.2,3.4)\end{array}$ & NA & $50-85$ & NA \\
\hline $\begin{array}{l}\text { Bennett, Steyvers (2020) } \\
\text { - re-analysis of } \\
\text { Bendavid et al. }(2020)\end{array}$ & $\begin{array}{l}\text { Santa Clara } \\
\text { county } \\
\text { (USA) }\end{array}$ & 3,324 & $04 / 2020$ & $0.27-3.21$ & NA & $5-65$ & NA \\
\hline Gudbjartsson et al. (2020) & Iceland & & & & & & \\
\hline Targeted testing 1 & & 177 & $01-03 / 2020$ & 9.2 & 13.6 & NA & NA \\
\hline Population screening 1 & & 10,797 & $03 / 2020$ & 0.8 & 41.4 & NA & NA \\
\hline Targeted testing 2 & & 7,275 & $03 / 2020$ & 14.4 & 5.7 & NA & NA \\
\hline $\begin{array}{l}\text { Population screening } 2 \\
\text { (Random sample) }\end{array}$ & & 2,283 & $04 / 2020$ & 0.6 & 53.8 & NA & NA \\
\hline LAPH (2020) & $\begin{array}{l}\text { Los Angeles } \\
\text { county } \\
\text { (USA) }\end{array}$ & & $04 / 2020$ & $\begin{array}{c}4.1 \\
(2.8,5.6)\end{array}$ & NA & $28-55$ & NA \\
\hline $\begin{array}{l}\text { Lavezzo et al. }(2020)^{1} \\
\text { First survey }\end{array}$ & $\begin{array}{l}\text { Vo } \\
\text { (Italy) }\end{array}$ & 2,812 & $02 / 2020$ & $\begin{array}{c}2.6^{2} \\
(2.1,3.3)\end{array}$ & 41.1 & NA & NA \\
\hline Second survey & & 2,343 & $03 / 2020$ & $\begin{array}{c}1.2^{2} \\
(0.8,11.8)\end{array}$ & 44.8 & NA & NA \\
\hline Nishiura et al. $(2020)^{1}$ & $\begin{array}{l}\text { Wuhan } \\
{\text { (China) })^{3}}^{\text {Con }}\end{array}$ & 565 & $02 / 2020$ & 1.4 & 62.5 & $5-20$ & $0.3-0.6$ \\
\hline Russell et al. $(2020)^{1}$ & $\begin{array}{l}\text { Diamond } \\
\text { Princess } \\
\text { cruise ship }\end{array}$ & 3,711 & $02 / 2020$ & 17 & 51.4 & NA & $\begin{array}{c}1.3 \\
(0.38,3.6)\end{array}$ \\
\hline Shakiba et al. (2020) & $\begin{array}{l}\text { Guilan } \\
\text { province } \\
\text { (Iran) }\end{array}$ & 551 & $04 / 2020$ & $\begin{array}{c}33^{4} \\
(28,39)\end{array}$ & 18 & NA & $0.08-0.12$ \\
\hline Streeck et al. (2020) & $\begin{array}{l}\text { Gangelt } \\
\text { (Germany) }\end{array}$ & 919 & $03 / 2020$ & $\begin{array}{c}15.5 \\
(12.3,19)\end{array}$ & 22.2 & 5 & $\begin{array}{c}0.36 \\
(0.29,0.45)\end{array}$ \\
\hline
\end{tabular}

Source: own compilation. Notes: ${ }^{1}$ full survey or nearly full survey, ${ }^{2}$ only active infections (not including seroprevalence), ${ }^{3}$ Japanese citizens evacuated from Wuhan (China), ${ }^{4}$ adjusted for test performance.

supports previous findings in the literature on empirical and model-based approaches towards infectious disease spreads in the past (Charaudeau et al. 2014, Dalziel et al. 2014, Findlater, Bogoch 2018).

Taking a look at state-specific effects, the results show a significantly higher average growth rate in Bavarian counties and lower growth rates in Saxony and North Rhine Westphalia, while Saarland and Baden-Wuerttemberg counties did not deviate from the national average. Thus, no dampening effect on pandemic growth can be confirmed for German states with additional curfews for the containment of the virus spread (Bavaria, Saarland, Saxony). The growth rate in Bavaria is even considerably above the average, although the time since the virus emerged and the current prevalence were included into the models as control variables.

With respect to the determinants of mortality, few clear statements can be made. SARS-CoV-2/COVID-19 mortality on the county level is not significantly influenced by demographic, spatial or mobility factors. However, these variables explain the regional growth rate, which was added to the mortality model as a control variable (and is significant, as expected). There is no specific "East Germany effect" as well.

Considering previous studies on the influence of air pollution on COVID-19 severity (Ogen 2020, Wu et al. 2020), it was expected that particulate matter and $\mathrm{NO}_{2}$ concentration would have an influence on mortality. Although it is plausible to assume that air pollution increases fatality rates of respiratory diseases, this hypothesis was not confirmed 
in the present study, which may result from an obvious data problem: The annual mean values of daily pollution was obtained on the level of monitoring stations, which are not evenly distributed across the counties and measure the air pollutant level at a specific point (e.g. traffic crossroad). It is unlikely that these obtained values are representative for the whole county. Thus, the validity of this indicator is questionable. Unfortunately, county-based data towards air pollution is not available nationwide.

Obviously, the variance of regional mortality reflects the regional variance of infected individuals belonging to the "risk group", defined as people of 60 years and above. Although no regional data is available for cases and deaths in retirement homes, a large share should be attributed to these facilities. Nationwide, people accommodated in facilities for the care of elderly make up at least 2,473 of 6,831 deaths (36.20\%) as of May 5, 2020 (RKI 2020a). The share of residents of retirement homes in all COVID-19-related deaths is equal to $51 \%$ in France and $33 \%$ in Denmark, ranging internationally from $11 \%$ in Singapore to $62 \%$ in Canada (Comas-Herrera et al. 2020). The relevance of retirement homes in Germany can be underlined with examples based on information available in local media which depicts the regional situation:

- In the city of Wolfsburg (Lower Saxony), the current mortality (MRT) is equal to 41.08 deaths per 100,000 inhabitants, while the current case fatality rate (CFR) is the highest in all German counties $(17.89 \%)$. Both values are calculated from the data used here (of date May 5, 2020). As of May 11, there have been 51 deaths attributed to COVID-19 in Wolfsburg, with 44 of these deaths (86.27\%) stemming from residents of one retirement home (Wolfsburger Nachrichten 2020).

- In the Hessian Odenwaldkreis with MRT $=54.75$ and $\mathrm{CFR}=14.60 \%, 29$ people who tested positive to SARS-CoV-2/COVID-19 died until April 14, 2020, 21 of them $(72.41 \%)$ were living in retirements homes in this county (Echo online 2020).

- In the city of Würzburg (Bavaria) with MRT $=38.32$ and CFR $=10.75 \%$, there have been 44 COVID-19 positive deceased in two retirement homes until April 24, 2020, leading to investigations by the public prosecution authorities (BR24 2020). Up to April 23, 2020, in the whole administrative district Unterfranken, $64 \%$ of all people who died from or with Corona were residents of retirement homes for elderly people (Mainpost 2020).

With respect to state-specific effects, there is a clear significant impact regarding Bavaria: Although the measures in Bavaria, based on the Austrian model, were probably the strictest of all German states, both regional growth rates and mortality are significantly higher than in the other states. This effect is isolated, as other effects (time, population density etc.) were controlled. In addition, the share of individuals belonging to the "risk group" is slightly higher in Bavaria. In the other states with curfews, Saarland and Saxony, no significant impact of this additional intervention was found, especially with respect to mortality which does not differ significantly from other states.

\section{Conclusions and limitations}

In the present study, regional SARS-CoV-2/COVID-19 growth was analyzed as an empirical phenomenon from a spatiotemporal perspective. Using infection dates estimated from reported cases, logistic growth models were estimated for the disease spread at the level of German counties as well as at the national level. The resulting intrinsic growth rates vary across the 412 German counties. The inflection points of the epidemic curves were contrasted to the dates where nonpharmaceutical interventions against the disease spread came into force. As a result, Germany as a whole as well as the majority of German counties have experienced a decline of the infection rate - which means a flattening of the infection curve - before the main social-related measures (contact ban, ban of gatherings and closure of "nonessential" services) were established. In a minority of counties, curve flattening even occured before schools and child day care facilities were closed. In contrast, some regional trend changes took place several weeks after the measures came into force. Due to this temporal mismatch, we have to conclude that the decline of infections cannot 


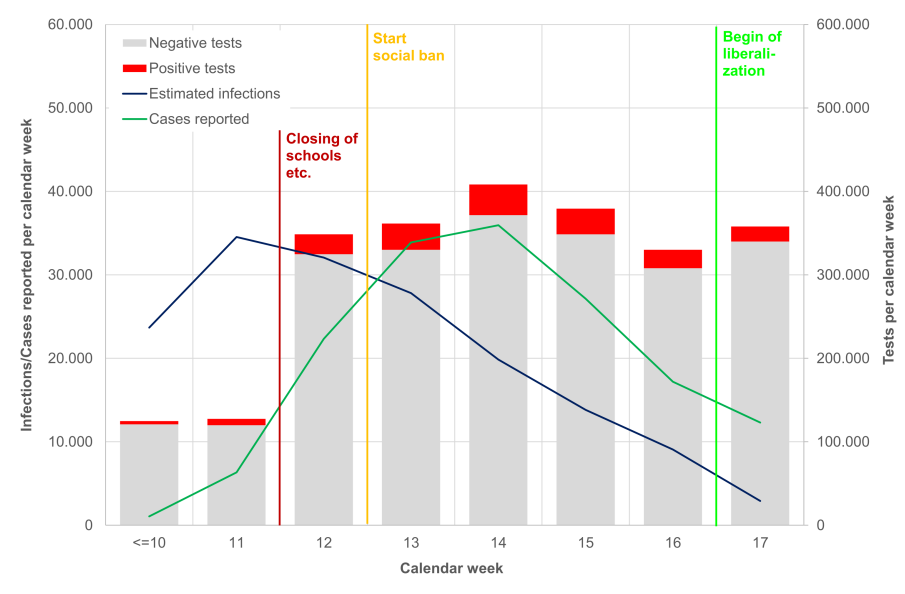

Figure 12: Estimated infections, reported cases and conducted tests by calendar week Source: own illustration. Data source: own calculations based on RKI $(2020 \mathrm{~b}, \mathrm{c})$

be causally linked to the "lockdown" of March 23. Moreover, also the impact of school and child care infrastructure closures on the pandemic spread remains questionable.

However, this does not mean that the disease spread slows down automatically. Four possible reasons have been identified for curve flattening independent from school closures and the "lockdown", with the first two relating to other types of (state-run and voluntary) measures which could reduce the transmission of an infectious disease: 1) Positive effects of previous governmental nonpharmaceutical interventions (especially the cancellation of large-scale events), 2) voluntary behavior changes (e.g., with respect to physical distancing and hygiene), 3) seasonality of the virus, and 4) a rising but undiscovered level of immunity within the population. However, whether these determinants may have contributed to the decline of infections, is outside the scope of the model-based analysis.

The determinants of regional intrinsic growth rates (as an indicator for the speed of pandemic spread) and mortality (as an indicator of the disease's severity) were explored using regression models. Among other things, regional pandemic growth is found to be driven by inter-regional mobility. Mortality on the county level obviously depends on the share of infected individuals belonging to the "risk group" (people of age 60 or older). This share is considerably influenced by SARS-CoV-2/COVID-19 outbreaks in retirement homes for the eldery, which have occurred in many German counties. Obviously, neither strict measures in Germany nor other countries were able to prevent these location-specific outbreaks. By consequence, it must be concluded that the severity of SARS-CoV-2/COVID-19 depends on the local/regional ability to protect the "risk group", especially older people in care facilities. This is the more important as virus transmission in care homes is nearly independent from the nonpharmaceutical interventions concerning e.g. schools, commercial services, and private residences. Three German states (Bavaria, Saarland, Saxony) established curfews additional to the nationwide interventions. We must conclude that these state-specific curfews did not contribute to a more positive outcome with respect to growth speed and mortality.

On the one hand, these findings pose the question as to whether contact bans and curfews are appropriate measures for containing the virus spread, especially when weighing the effects against the social and economic consequences as well as the curtailment of civil rights. On the other hand, when looking at regional mortality and case fatality rate, the protection of "risk groups", especially older people in retirement homes, is obviously of moderate success.

From the methodological point of view, two further conclusions must be stated: Nonpharmaceutical interventions aim at the reduction of new infections, thus, their impact must be assessed regarding temporal coincidences with new infections. Regardless of the modeling approach used for the analysis of pandemic spread, any analysis concerning the effectiveness of nonpharmaceutical interventions must be based on realistic infection 
dates rather than reporting dates of infected persons. An over- or underestimation of the time between infection and report - in particular, the reporting delay - might lead to senseless conclusions towards the influence of specific measures. Estimating the true infection dates from reported cases in official statistics is the biggest methodological challenge in this context. Moreover, the present study reveals the importance of a spatial perspective on pandemic spread: Spatially varying growth rates and severity measures show that the spread of an infectious disease is to be regarded as a spatiotemporal phenomenon. Thus, further studies should address regional differences of epidemiological variables with respect to transmission.

However, despite these conclusions, the study is faced with two important limitations:

- One has to keep in mind that previous model-based simulation studies which prove the effectiveness of nonpharmaceutical interventions already make a priori assumptions about the impact of these measures: In particular, the input parameters of the epidemiological models (such as the intensity of physical contacts between individuals) are set in a way that interventions (such as school closures or social distancing) reduce the transmission of the virus in any case and, thus, the simulation output shows a decline of infections subsequent to these interventions (an der Heiden, Buchholz 2020, Ferguson et al. 2020). This type of modeling approach (and the corresponding results) might be regarded either as a "causal model" or a tautology. In contrast, the modeling approach used here is of purely empirical nature, only incorporating time series of infections. By consequence, the results are not causal but correlative with respect to the presence or absence of temporal coincidences. It can be shown that curve flattening does not coincide with the focused interventions but occurred after previous interventions and might be due to several other causes. However, the actual reasons why the infections declined cannot be deduced from modeling results but must be explored based on interpretations of several empirical hints. Furthermore, as the focus is on inflection points and trend changes, respectively, the present empirical analysis cannot rule out additional impacts of the German "lockdown", e.g., in terms of a stabilization effect.

- Finally, it is necessary to take a look at the quality of the data on reported cases of SARS-CoV-2/COVID-19 used here. While several statistical uncertainties have been addressed by estimating the dates of infection in the present study, the method of data collection also raises concerns. The confirmed cases of infections reported by regional health departments to the RKI result from SARS-CoV-2 tests conducted in the case of specific symptoms. When aggregating the reported cases to time series and analyzing their temporal evolvement, it is implictly assumed that the testing strategy remains the same over time. However, the number of tests was increased enormously during the pandemic - which is to be welcomed from the point of view of public health. From a statistic perspective, it might cause a bias because an increase in testing must result in an increase of reported infections, as a larger share of infections is revealed, all other things being equal. In his statistical study, Kuhbandner (2020) argues that the detected SARS-CoV-2 pandemic growth is mainly due to increased testing, leading to the conclusion that "the scenario of a pandemic spread of the Coronavirus in based on a statistical fallacy". To confirm or deny this conclusion is not subject of the present study. However, taking a look at the conducted tests per calendar week (see Figure 12) reveals weekly differences. From calendar week 11 to 12 , there has been an increase of conducted tests from 127,457 ( $5.9 \%$ positive) to 348,619 ( $6.8 \%$ positive), which means a raise by factor 2.7. The maximum of tests was conducted in CW 14 (408,348 with $9.0 \%$ positive results), decreasing beyond that time, rising again in CW 17. The absolute number of positive tests is reflected plausibly in the number of reported cases (green line), as the confirmed cases result from the tests. The most estimated infections occurred in CW 11 and 12, showing again the delay between infection and case confirmation. Apart from the fact that excessive testing is probably the best strategy to control the spread of a virus, the resulting statistical data may suffer from underestimation and overestimation, dependent on which time period is regarded. 


\section{References}

Al-Tawfiq J, Rodriguez-Morales A (2020) Super-spreading events and contribution to transmission of MERS, SARS, and SARS-CoV-2 (COVID-19). Journal of Hospital Infection 105: 111-112. CrossRef.

an der Heiden M, Buchholz U (2020) Modellierung von Beispielszenarien der SARS-CoV2-Epidemie 2020 in Deutschland. Report. https://doi.org/10.25646/6571.2 (accessed May 09, 2020)

an der Heiden M, Hamouda O (2020) Schätzung der aktuellen Entwicklung der SARSCoV-2-Epidemie in Deutschland - Nowcasting. Epidemiologisches Bulletin 17: 10-16. CrossRef.

Araujo MB, Naimi B (2020) Spread of SARS-CoV-2 Coronavirus likely to be constrained by climate. medRxiv. CrossRef.

Backer JA, Klinkenberg D, Wallinga J (2020) Incubation period of 2019 novel coronavirus (2019-nCoV) infections among travellers from Wuhan, China, 20-28 January 2020. Eurosurveillance 25. CrossRef.

Batista M (2020a) Estimation of the final size of the coronavirus epidemic by the logistic model (Update 4). Preprint. https://www.researchgate.net/publication/339240777_Estimation_of_the_final_size_of_coronavirus_epidemic_by_the_logistic_model

Batista M (2020b) Estimation of the final size of the coronavirus epidemic by the SIR model. Preprint. https://www.researchgate.net/profile/Milan_Batista/publication/339311383_Estimation_of_the_final_size_of_the_coronavirus_epidemic_by_the_SIR_model/links/5e767fca4585157b9a512f80/Estimation-of-the-final-size-of-the-coronavirusepidemic-by-the-SIR-model.pdf

BBSR - Bundesinstitut für Bau, Stadt- und Raumforschung (2020) Wo in Deutschland die Lebenserwartung am höchsten ist. Dataset. https://www.bbsr.bund.de/BBSR/DE/Home/Topthemen/interaktive-karten/lebenserwartung/lebenserwartung.html (accessed May 01, 2020)

Ben-Israel I (2020) The end of exponential growth: The decline in the spread of coronavirus. The Times of Israel, 19 April 2020. https://www.timesofisrael.com/theend-of-exponential-growth-the-decline-in-the-spread-of-coronavirus/ (accessed May 07, 2020)

Bendavid E, Mulaney B, Sood N, Shah S, Ling E, Bromley-Dulfano R, Lai C, Weissberg Z, Saavedra-Walker R, Tedrow J, Tversky D, Bogan A, Kupiec T, Eichner D, Gupta R, Ioannidis J, Bhattacharya J (2020) COVID-19 Antibody Seroprevalence in Santa Clara County, California. medRxiv. CrossRef.

Bennett ST, Steyvers M (2020) Estimating COVID-19 Antibody Seroprevalence in Santa Clara County, California. A re-analysis of Bendavid et al. medRxiv. CrossRef.

Bivand RS, Pebesma E, Gomez-Rubio V (2013) Applied spatial data analysis with $R$ (second ed.). Springer, NY

BR24 - Bayerischer Rundfunk (2020) Corona: Vorermittlungen gegen weiteres Würzburger Seniorenheim. Online article of April 24, 2020. https://www.br.de/nachrichten/bayern/corona-vorermittlungen-gegen-weiteres-wuerzburger-seniorenheim,Rx4vSyc (accessed May 12, 2020)

Braun J, Loyal L, Frentsch M, Wendisch D, Georg P, Kurth F, Hippenstiel S, Dingeldey M, Kruse B, Fauchere F, Baysal E, Mangold M, Henze L, Lauster R, Mall M, Beyer K, Roehmel J, Schmitz J, Miltenyi S, Mueller MA, Witzenrath M, Suttorp N, Kern F, Reimer U, Wenschuh H, Drosten C, Corman VM, Giesecke-Thiel C, Sander LE, Thiel A (2020) Presence of SARS-CoV-2 reactive T cells in COVID-19 patients and healthy donors. medRxiv. CrossRef. 
Broberg E, Nicoll A, Amato-Gauci A (2011) Seroprevalence to influenza A(H1N1) 2009 virus - where are we? Clinical and vaccine immunology 18: 1205-1212. CrossRef.

Buchholz U, Buda S, Prahm K (2020) Abrupter Rückgang der Raten an Atemwegserkrankungen in der deutschen Bevölkerung. Epidemiologisches Bulletin 16: 7-9. CrossRef.

Capital (2020) Thomas Straubhaar: Die öffentliche Meinung wird kippen. Online article of March 21, 2020. https://www.capital.de/wirtschaft-politik/thomas-straubhaar-dieoeffentliche-meinung-wird-kippen (accessed March 23, 2020)

Carvalho Aguiar Melo M, de Sousa Soares D (2020) Impact of social distancing on mental health during the COVID-19 pandemic: An urgent discussion. International Journal of Social Psychiatry 66: 625-626. CrossRef.

Charaudeau S, Pakdaman K, Boëlle PY (2014) Commuter Mobility and the Spread of Infectious Diseases: Application to Influenza in France. PLOS ONE 9: 1-9. CrossRef.

Chi G, Zhu J (2008) Spatial Regression Models for Demographic Analysis. Population Research and Policy Review 27: 17-42. CrossRef.

Chowell G, Simonsen L, Viboud C, Yang K (2014) Is West Africa Approaching a Catastrophic Phase or is the 2014 Ebola Epidemic Slowing Down? Different Models Yield Different Answers for Liberia. PLoS currents 6. CrossRef.

Chowell G, Viboud C, Hyman J, Simonsen L (2015) The Western Africa Ebola Virus Disease Epidemic Exhibits Both Global Exponential and Local Polynomial Growth Rates. PLOS Currents Outbreaks. CrossRef.

CNN - Cable News Network (2020) China goes into emergency mode as number of confirmed Wuhan coronavirus cases reaches 2,700. Online article of January 27, 2020. https://edition.cnn.com/2020/01/26/asia/wuhan-coronavirus-update-intl-hnk/index.hitml (accessed May 8, 2020)

Comas-Herrera A, Zalakaín J, Litwin C, Hsu AT, Lane N, Fernández JL (2020) Mortality associated with COVID-19 outbreaks in care homes: early international evidence (Last updated 3 May 2020). Report, International Long-term Care Policy Network. https://ltccovid.org/wp-content/uploads/2020/05/Mortality-associated-withCOVID-3-May-final-6.pdf (accessed May 12, 2020)

Covid-19 Mobility Project (2020a) First Report: Mobility in Germany and Social Distancing (April 5, 2020). Website. https://www.covid-19-mobility.org/reports/first-reportgeneral-mobility/ (accessed August 13, 2020).

Covid-19 Mobility Project (2020b) Second Report: Mobility on the rise (April 15, 2020). Website. https://www.covid-19-mobility.org/reports/second-report/ (accessed August 13, 2020).

Dalziel BD, Pourbohloul B, Ellner SP (2014) Human mobility patterns predict divergent epidemic dynamics among cities. Proceedings. Biological sciences 280: 20130763. CrossRef.

Destatis (2020a) Beherbergungsbetriebe, Schlafgelegenheiten, Gästeankünfte, Gästeübernachtungen - Jahressumme - regionale Tiefe: Kreise und krfr. Städte (ab 2018) (Tab. 45412-01-03-4). Dataset. https://www.regionalstatistik.de/genesis/online/ (accessed August 13, 2020), dl-de/by-2-0

Destatis (2020b) Bevölkerung: Kreise, Stichtag, Altersgruppen - Fortschreibung des Bevölkerungsstandes (Tab. 12411-0017). Dataset. https://www.regionalstatistik.de/genesis/online/ (accessed May 6, 2020), dl-de/by-2-0

Destatis (2020c) Sozialversicherungspflichtig Beschäftigte am Arbeits- und Wohnort, Ein- und Auspendler über Kreisgrenzen nach Geschlecht - Stichtag 30.06. - regionale 
Ebenen (Tab. 13111-09-01-4-B). Dataset. https://www.regionalstatistik.de/genesis/online/ (accessed August 14, 2020), dl-de/by-2-0

Deutsche Welle (2020a) Coronavirus: What are the lockdown measures across Europe? Online article of April 14, 2020. https://www.dw.com/en/coronavirus-what-are-thelockdown-measures-across-europe/a-52905137 (accessed May 8, 2020)

Deutsche Welle (2020b) What are Germany's new coronavirus social distancing rules? Online article of March 22, 2020. https://www.dw.com/en/what-are-germanys-newcoronavirus-social-distancing-rules/a-52881742 (accessed May 8, 2020)

D'Souza G, Dowdy D (2020) What is Herd Immunity and How Can We Achieve It With COVID-19? Online article of April 10, 2020. https://www.jhsph.edu/covid19/articles/achieving-herd-immunity-with-covid19.html (accessed May 10, 2020)

Echo online (2020) Coronavirus: Altenheime im Odenwaldkreis beklagen 21 Tote. Online article of April 14, 2020. https://www.echo-online.de/lokales/odenwaldkreis/odenwaldkreis/coronavirus-altenheime-im-odenwaldkreis-beklagen-21-tote_21547352 (accessed May 12, 2020)

Engel J (2010) Parameterschätzen in logistischen Wachstumsmodellen. Stochastik in der Schule 1: 13-18. CrossRef.

Engina AB, Engin ED, Engin A (2020) Two important controversial risk factors in SARSCoV-2 infection: Obesity and smoking. Environmental toxicology and pharmacology 78 : 103411. CrossRef.

European Centre for Disease Prevention and Control (2020) COVID-19 situation update worldwide, as of 10 May 2020 . Website. https://www.ecdc.europa.eu/en/geographicaldistribution-2019-ncov-cases (accessed May 11, 2020)

Ferguson NM, Laydon D, Nedjati-Gilani G, Imai N, Ainslie K, Baguelin M, Bhatia S, Boonyasiri A, Cucunubá Z, Cuomo-Dannenburg G, Dighe A, Dorigatti I, Fu H, Gaythorpe K, Green W, Hamlet A, Hinsley W, Okell LC, van Elsland S, Thompson H, Verity R, Volz E, Wang H, Wang Y, Walker PG, Walters C, Winskill P, Whittaker C, Donnelly CA, Riley S, Ghani AC (2020) Report 9: Impact of non-pharmaceutical interventions (NPIs) to reduce COVID-19 mortality and healthcare demand (16 March 2020). Report, Imperial College COVID-19 Response Team. https://www.imperial.ac.uk/media/imperial-college/medicine/mrc-gida/202003-16-COVID19-Report-9.pdf (accessed May 12, 2020)

Findlater A, Bogoch II (2018) Human Mobility and the Global Spread of Infectious Diseases: A Focus on Air Travel. Trends in Parasitology 34: 772-783. CrossRef.

Fine P, Eames K, Heymann DL (2011) "Herd Immunity": A Rough Guide. Clinical Infectious Diseases 52: 911-916. CrossRef.

Focus (2020) Bei 9 Grad fühlt sich Corona am wohlsten: Verschwindet das Virus im Sommer? Online article of April 14, 2020. https://www.focus.de/gesundheit/ratgeber/erkaeltung/neue-modellrechnung-bei-9-grad-fuehlt-sich-corona-amwohlsten-verschwindet-das-virus-im-sommer_id_11885151.html (accessed May 10, 2020)

Fox J, Weisberg S (2019) An R Companion to Applied Regression (3rd ed.). Sage, Thousand Oaks CA

Gomes MGM, Corder RM, King JG, Langwig KE, Souto-Maior C, Carneiro J, Goncalves G, Penha-Goncalves C, Ferreira MU, Aguas R (2020) Individual variation in susceptibility or exposure to SARS-CoV-2 lowers the herd immunity threshold. medRxiv. CrossRef.

Greene WH (2012) Econometric Analysis. Seventh Edition. Pearson

Griffith D (2009) Spatial Autocorrelation. In: Kitchin R, Thrift N (eds), International Encyclopedia of Human Geography. 308-316 
Grifoni A, Weiskopf D, Ramirez SI, Mateus J, Dan JM, Moderbacher CR, Rawlings SA, Sutherland A, Premkumar L, Jadi RS, Marrama D, de Silva AM, Frazier A, Carlin AF, Greenbaum JA, Peters B, Krammer F, Smith DM, Crotty S, Sette A (2020) Targets of T Cell Responses to SARS-CoV-2 Coronavirus in Humans with COVID-19 Disease and Unexposed Individuals. Cell. CrossRef.

Gudbjartsson DF, Helgason A, Jonsson H, Magnusson OT, Melsted P, Norddahl GL, Saemundsdottir J, Sigurdsson A, Sulem P, Agustsdottir AB, Eiriksdottir B, Fridriksdottir R, Gardarsdottir EE, Georgsson G, Gretarsdottir OS, Gudmundsson KR, Gunnarsdottir TR, Gylfason A, Holm H, Jensson BO, Jonasdottir A, Jonsson F, Josefsdottir KS, Kristjansson T, Magnusdottir DN, le Roux L, Sigmundsdottir G, Sveinbjornsson G, Sveinsdottir KE, Sveinsdottir M, Thorarensen EA, Thorbjornsson B, Löve A, Masson G, Jonsdottir I, Möller AD, Gudnason T, Kristinsson KG, Thorsteinsdottir U, Stefansson K (2020) Spread of SARS-CoV-2 in the Icelandic Population. New England Journal of Medicine. CrossRef.

Guth D, Holz-Rau C, Maciolek M (2010) Indikatoren für Berufspendelanalysen. Datengrundlagen und Anwendungsbeispiele. Raum und Mobilität. Arbeitspapiere des Fachgebiets Verkehrswesen und Verkehrsplanung der TU Dortmund, 18. http://www.vpl.tu-dortmund.de/cms/Medienpool/PDF_Dokomunte/Arbeitspapiere/AP18_von_Dennis_Guth_und_Christian_Holz-Rau_und_Markus_Maciolek.pdf (accessed August 15, 2020)

Hlavac M (2018) stargazer: Well-Formatted Regression and Summary Statistics Tables. Bratislava, Slovakia: Central European Labour Studies Institute (CELSI). R package version 5.2 .2

IBBS - Informationsstelle des Bundes für Biologische Gefahren und Spezielle Pathogene (2020) 2019-nCoV: Verdachtsabklärung und Maßnahmen. Technical report. CrossRef.

Ipsos (2020) Internationale Umfrage: Mehrheit empfindet Coronavirus als große Bedrohung. Press release from February 12, 2020. https://www.ipsos.com/sites/default/files/ct/news/documents/2020-02/ipsos-pi_coronavirus_feb2020.pdf (accessed May 11, 2020)

Johns Hopkins University (2020) New Cases of COVID-19 In World Countries. Website. https://coronavirus.jhu.edu/data/new-cases (accessed May 11, 2020)

Kaw AK, Kalu EE, Nguyen D (2011) Numerical Methods with Applications. http://nm.mathforcollege.com/topics/textbook_index.html (accessed May 08, 2020)

Kuhbandner C (2020) The Scenario of a Pandemic Spread of the Coronavirus SARS-CoV-2 is Based on a Statistical Fallacy. Preprint. CrossRef.

Lai CC, Shih TP, Ko WC, Tang HJ, Hsueh PR (2020) Severe acute respiratory syndrome coronavirus 2 (SARS-CoV-2) and coronavirus disease-2019 (COVID-19): The epidemic and the challenges. International Journal of Antimicrobial Agents 55: 105924. CrossRef.

LAPH - Los Angeles County Department of Public Health (2020) USC-LA County Study: Early Results of Antibody Testing Suggest Number of COVID-19 Infections Far Exceeds Number of Confirmed Cases in Los Angeles County. Press release from April 20, 2020. http://publichealth.lacounty.gov/phcommon/public/media/mediapubhpdetail.cfm?prid=2328 (accessed May 09, 2020

Lauer SA, Grantz KH, Bi Q, Jones FK, Zheng Q, Meredith HR, Azman AS, Reich NG, Lessler J (2020, 03) The Incubation Period of Coronavirus Disease 2019 (COVID-19) From Publicly Reported Confirmed Cases: Estimation and Application. Annals of Internal Medicine. CrossRef.

Lavezzo E, Franchin E, Ciavarella C, Cuomo-Dannenburg G, Barzon L, Del Vecchio C, Rossi L, Manganelli R, Loregian A, Navarin N, Abate D, Sciro M, Merigliano S, Decanale E, Vanuzzo MC, Saluzzo F, Onelia F, Pacenti M, Parisi S, Carretta G, Donato D, Flor L, Cocchio S, Masi G, Sperduti A, Cattarino L, Salvador R, Gaythorpe KA, , 
Brazzale AR, Toppo S, Trevisan M, Baldo V, Donnelly CA, Ferguson NM, Dorigatti I, Crisanti A (2020) Suppression of COVID-19 outbreak in the municipality of Vo, Italy. medRxiv. CrossRef.

Leung C (2020) The difference in the incubation period of 2019 novel coronavirus (SARSCoV-2) infection between travelers to Hubei and nontravelers: The need for a longer quarantine period. Infection Control \& Hospital Epidemiology 41: 594-596. CrossRef.

Li MY (2018) An Introduction to Mathematical Modeling of Infectious Diseases. Springer International Publishing

Li Q, Guan X, Wu P, Wang X, Zhou L, Tong Y, Ren R, Leung KS, Lau EH, Wong JY, Xing X, Xiang N, Wu Y, Li C, Chen Q, Li D, Liu T, Zhao J, Liu M, Tu W, Chen C, Jin L, Yang R, Wang Q, Zhou S, Wang R, Liu H, Luo Y, Liu Y, Shao G, Li H, Tao Z, Yang Y, Deng Z, Liu B, Ma Z, Zhang Y, Shi G, Lam TT, Wu JT, Gao GF, Cowling BJ, Yang B, Leung GM, Feng Z (2020) Early Transmission Dynamics in Wuhan, China, of Novel Coronavirus-Infected Pneumonia. New England Journal of Medicine 382: 1199-1207. CrossRef.

Linton N, Kobayashi T, Yang Y, Hayashi K, Akhmetzhanov A, Jung SM, Yuan B, Kinoshita R, Nishiura H (2020) Incubation period and other epidemiological characteristics of 2019 novel coronavirus infections with right truncation: A statistical analysis of publicly available case data. Journal of Clinical Medicine 9: 538. CrossRef.

Ma J (2020) Estimating epidemic exponential growth rate and basic reproduction number. Infectious Disease Modelling 5: 129-141. CrossRef.

Mainpost (2020) Hat Unterfranken das Coronavirus bald besiegt? Online article of May 8, 2020. https://www.mainpost.de/regional/wuerzburg/hat-unterfranken-das-coronavirusbald-besiegt;art735,10443791 (accessed May 12, 2020)

Mak TW, Saunders ME (2006) Immunity to Pathogens. The Immune Response: 641-694. CrossRef.

Mitterer B (2013) Raumbezogene Lebensstile und Konsummuster - eine Annäherung an die Dorfbewohner des 21. Jahrhunderts. Untersucht an zwei Gemeinden im Einzugsgebiet von Großstädten. PhD thesis, Universität Würzburg. https://opus.bibliothek.uniwuerzburg.de/files/9811/Dissertation_Mitterer_Brigitte_Raumbezogene_Lebensstile.pdf (accessed August 21, 2020).

Moriyama M, Hugentobler WJ, Iwasaki A (2020) Seasonality of Respiratory Viral Infections. Annual Review of Virology 7: 83-101. CrossRef.

Mucci F, Mucci N, Diolaiuti F (2020) Super-spreading events and contribution to transmission of MERS, SARS, and SARS-CoV-2 (COVID-19). Clinical Neuropsychiatry 17: 63-64. CrossRef.

New York Times (2020) A New Covid-19 Crisis: Domestic Abuse Rises Worldwide. Online article of April 6, 2020. https://www.nytimes.com/2020/04/06/world/coronavirusdomestic-violence.html (accessed May 10, 2020)

Nishiura H, Kobayashi T, Yang Y, Hayashi K, Miyama T, Kinoshita R, Linton NM, Jung SM, Yuan B, Suzuki A, Akhmetzhanov AR (2020) The Rate of Underascertainment of Novel Coronavirus (2019-nCoV) Infection: Estimation Using Japanese Passengers Data on Evacuation Flights. Journal of clinical medicine 9: 419. CrossRef.

Ogen Y (2020) Assessing nitrogen dioxide (NO2) levels as a contributing factor to coronavirus (COVID-19) fatality. Science of The Total Environment 726: 138605. CrossRef.

Padberg J, Bauer T (2006) Erkältungskrankheiten. Deutsche Medizinische Wochenschrift 131. CrossRef.

REGION: Volume 7, Number 2, 2020 
Pell B, Kuang Y, Viboud C, Chowell G (2018) Using phenomenological models for forecasting the 2015 ebola challenge. Epidemics 22: 62 - 70. CrossRef.

Petermann S (2001) Soziale Vernetzung städtischer und ländlicher Bevölkerungen am Beispiel der Stadt Halle. Abschlussbericht und Codebuch. Report. https://www2.soziologie.uni-halle.de/publikationen/pdf/0102.pdf (accessed August 21, 2020).

Porta M (2008) A Dictionary of Epidemiology. Oxford University Press

QGIS Development Team (2019) QGIS Geographic Information System. Open Source Geospatial Foundation. http://qgis.osgeo.org

R Core Team (2019) R: A language and environment for statistical computing. Software:, Vienna, Austria. https://www.R-project.org/

Rheinische Post online (2020) Hamsterkäufe und leere Regale. Online article of February 28, 2020. https://rp-online.de/wirtschaft/hamsterkaeufe-und-leere-regale-bei-aldi-lidlund-co_aid-49285165 (accessed May 10, 2020)

Ritz C, Streibig JC (2008) Nonlinear Regression with R. Springer

RKI - Robert Koch Institut (2020a) Coronavirus Disease 2019 (COVID-19) - Daily Situation Report of the Robert Koch Institute 05/05/2020. Report. https://www.rki.de/DE/Content/InfAZ/N/Neuartiges_Coronavirus/Situationsberichte/2020-05-05-en.pdf (accessed May 07, 2020)

RKI - Robert Koch Institut (2020b) Tabelle mit den aktuellen Covid-19 Infektionen pro Tag (Zeitreihe). Dataset. https://npgeo-corona-npgeo-de.hub.arcgis.com/datasets/dd4580c810204019a7b8eb3e0b329dd6_0/data (accessed May 05, 2020), dl-de/by-2-0

RKI - Robert Koch Institut (2020c) Täglicher Lagebericht des RKI zur CoronavirusKrankheit-2019 (COVID-19) 06.05.2020. Report. https://www.rki.de/DE/Content/InfAZ/N/Neuartiges_Coronavirus/Situationsberichte/2020-05-06-de.pdf (accessed May 11, 2020)

Rusche K (2008) Quality of Life in the Regions: An Exploratory Spatial Data Analysis for West German Labor Markets. CAWM Discussion Paper, 10. https://www.econstor.eu/obitstream/10419/51262/1/671597892.pdf (accessed August 15, 2020

Russell TW, Hellewell J, Jarvis CI, van Zandvoort K, Abbott S, Ratnayake R, working group CC, Flasche S, Eggo RM, Edmunds WJ, Kucharski AJ (2020) Estimating the infection and case fatality ratio for coronavirus disease (COVID-19) using ageadjusted data from the outbreak on the Diamond Princess cruise ship, February 2020. Eurosurveillance 25. CrossRef.

Süddeutsche Zeitung (2020a) Um jeden Preis? (guest commentary by René Schlott). Online article of March 17, 2020. https://www.sueddeutsche.de/leben/corona-reneschlott-gastbeitrag-depression-soziale-folgen-1.4846867 (accessed March 19, 2020)

Süddeutsche Zeitung (2020b) Wenn das Kind verborgen bleibt. Online article of May 6, 2020. https://www.sueddeutsche.de/politik/coronavirus-haeusliche-gewalt-jugendaemter-1.4899381?print=true (accessed May 11, 2020)

Selvan ME (2020) Risk factors for death from COVID-19. Nature Reviews Immunology 20: 407. CrossRef.

Shakiba M, Hashemi Nazari SS, Mehrabian F, Rezvani SM, Ghasempour Z, Heidarzadeh A (2020) Seroprevalence of COVID-19 virus infection in Guilan province, Iran. medRxiv. CrossRef.

Stedman M, Davies M, Lunt M, Verma A, Anderson SG, Heald AH (2020) A phased approach to unlocking during the COVID-19 pandemic - Lessons from trend analysis. International Journal of Clinical Practice 74: e13528. CrossRef. 
Stein RA (2011) Super-spreaders in infectious diseases. International Journal of Infectious Diseases 15: e510-e513. CrossRef.

Streeck H, Schulte B, Kuemmerer B, Richter E, Hoeller T, Fuhrmann C, Bartok E, Dolscheid R, Berger M, Wessendorf L, Eschbach-Bludau M, Kellings A, Schwaiger A, Coenen M, Hoffmann P, Noethen M, Eis-Huebinger AM, Exner M, Schmithausen R, Schmid M, Kuemmerer B (2020) Infection fatality rate of SARS-CoV-2 infection in a German community with a super-spreading event. medRxiv. CrossRef.

Stuttgarter Zeitung (2020) Gewaltambulanz verzeichnet deutlich mehr Kindesmisshandlungen. Online article of May 5, 2020. https://www.stuttgarter-zeitung.de/inhalt.coronavirus-in-baden-wuerttemberg-gewaltambulanz-verzeichnet-deutlich-mehr-kindesmisshandlungen.c73a0841-0538-4c80-9035-1e81436cfd47.html (accessed May 10, 2020)

Sun K, Chen J, Viboud C (2020) Early epidemiological analysis of the coronavirus disease 2019 outbreak based on crowdsourced data: a population-level observational study. The Lancet Digital Health 2: e201-e208. CrossRef.

Tagesschau.de (2020a) 16 Wege aus der Corona-Krise. Online article of May 8, 2020. https://www.tagesschau.de/inland/corona-lockerung-bundeslaender-103.html (accessed May 8, 2020)

Tagesschau.de (2020b) Obergrenze mehrfach überschritten. Online article of May 10, 2020. https://www.tagesschau.de/inland/corona-landkreise-105.html (accessed May 10, 2020)

Tagesschau.de (2020c) Quarantäne im Kreis Heinsberg teils beendet. Online article of March 1, 2020. https://www.tagesschau.de/inland/coronavirus-heinsberg-101.html (accessed May 10, 2020)

Tagesspiegel (2020a) Gibt keinen Grund, das ganze Land in häusliche Quarantäne zu schicken. Online article of March 24, 2020. https://www.tagesspiegel.de/politik/epidemiologe-warnt-vor-noch-schaerferen-massnahmen-gibt-keinen-grund-das-ganze-land-in-haeusliche-quarantaene-zu-schicken/25672822.html (accessed March 27, 2020)

Tagesspiegel (2020b) In diesen Regionen wütet das Coronavirus besonders stark weiter. Online article of April 21, 2020. https://www.tagesspiegel.de/gesellschaft/tirschenreuth-heinsberg-potsdam-in-diesen-regionen-wuetet-das-coronavirus-besonders-starkweiter/25755328.html (accessed March 27, 2020)

The Guardian (2020) 'Great Lockdown' to rival Great Depression with $3 \%$ hit to global economy, says IMF. Online article of April 14, 2020. https://www.theguardian.com/business /2020/apr/14/great-lockdown-coronavirus-to-rival-great-depression-with-3hit-to-global-economy-says-imf (accessed May 10, 2020)

Tsoularis A (2002) Analysis of logistic growth models. Mathematical Biosciences 179: 21 - 55. CrossRef.

Tveite H (2019) NNJoin: Nearest neighbour join. Join vector layers based on nearest neighbour relationships. http://arken.nmbu.no/ havatv/gis/qgisplugins/NNJoin/

UBA - Umweltbundesamt (2020a) Aktuelle Luftdaten - Jahresbilanzen. Website. https://www.umweltbundesamt.de/daten/luft/luftdaten/jahresbilanzen/ (accessed August $13,2020)$.

UBA - Umweltbundesamt (2020b) Stationsdatenbank - Downloads. Website. https://www.env-it.de/stationen/public/downloadRequest.do (accessed August 13, 2020).

Vasconcelos GL, Macêdo AMS, Ospina R, Almeida FAG, Duarte-Filho GC, Souza ICL (2020) Modelling fatality curves of covid-19 and the effectiveness of intervention strategies. medRxiv. CrossRef. 
Welt online (2020a) In Hamburg ist niemand ohne Vorerkrankung an Corona gestorben. Online article of April 8, 2020. https://www.welt.de/regionales/hamburg/article207086675/Rechtsmediziner-Pueschel-In-Hamburg-ist-niemand-ohne-Vorerkrankungan-Corona-gestorben.html (accessed April 8, 2020)

Welt online (2020b) Warum Ostdeutschland weniger von Corona betroffen ist. Online article of May 4, 2020. https://www.welt.de/wissenschaft/article207718789/Epidemiologezu-Corona-Darum-kommt-der-Osten-so-gut-durch-die-Pandemie.html (accessed May 8, 2020)

Wieland T (2019) REAT: A Regional Economic Analysis Toolbox for R. REGION 6: R1-R57. CrossRef.

Williams SN, Armitage CJ, Tampe T, Dienes K (2020) Public perceptions and experiences of social distancing and social isolation during the COVID-19 pandemic: A UK-based focus group study. medRxiv. CrossRef.

Wolfsburger Nachrichten (2020) Corona in Wolfsburg: Die Fakten auf einen Blick. Online article of May 11, 2020. https://www.wolfsburger-nachrichten.de/wolfsburg/article228716311/corona-wolfsburg-infizierte-geschaefte-bus-bahn-infos-informationenarzt.html (accessed May 12, 2020)

World Health Organization (2020a) Transmission of COVID-19 by asymptomatic cases. Website. http://www.emro.who.int/health-topics/corona-virus/transmission-of-covid19-by-asymptomatic-cases.html (accessed August 20, 2020)

World Health Organization (2020b) WHO announces COVID-19 outbreak a pandemic. Press release from March 12, 2020. http://www.euro.who.int/en/health-topics/healthemergencies/coronavirus-covid-19/news/news/2020/3/who-announces-covid-19-outbreak-a-pandemic (accessed May 10, 2020)

Wu K, Darcet D, Wang Q, Sornette D (2020) Generalized logistic growth modeling of the COVID-19 outbreak in 29 provinces in China and in the rest of the world. Technical report. Preprint: https://arxiv.org/ftp/arxiv/papers/2003/2003.05681.pdf (accessed April 24, 2020)

Wu X, Nethery RC, Sabath BM, Braun D, Dominici F (2020) Exposure to air pollution and COVID-19 mortality in the United States: A nationwide cross-sectional study. medRxiv. CrossRef.

Xia W, Liao J, Li C, Li Y, Qian X, Sun X, Xu H, Mahai G, Zhao X, Shi L, Liu J, Yu L, Wang M, Wang Q, Namat A, Li Y, Qu J, Liu Q, Lin X, Cao S, Huan S, Xiao J, Ruan F, Wang H, Xu Q, Ding X, Fang X, Qiu F, Ma J, Zhang Y, Wang A, Xing Y, $\mathrm{Xu}$ S (2020) Transmission of corona virus disease 2019 during the incubation period may lead to a quarantine loophole. medRxiv. CrossRef.

YouGov (2020) Der Corona-Tracker: Angst der Bevölkerung vor Virus wächst. Press release from March 17, 2020. https://yougov.de/news/2020/03/17/der-corona-trackerangst-der-bevolkerung-vor-virus / (accessed May 11, 2020)

Zhou X, Ma X, Hong N, Su L, Ma Y, He J, Jiang H, Liu C, Shan G, Zhu W, Zhang S, Long Y (2020) Forecasting the Worldwide Spread of COVID-19 based on Logistic Model and SEIR Model. medRxiv. CrossRef. 